\title{
Fostering Entrepreneurship: Promoting Founding or Funding?*
}

\author{
Thomas Hellmann ${ }^{\dagger}$ and Veikko Thiele
}

Forthcoming in Management Science

February 26, 2018

\begin{abstract}
Governments across the globe are eager to foster entrepreneurial ecosystems, yet there is no consensus on what policies to use. We develop a theory about the equilibrium consequences of two canonical types of entrepreneurship policies: policies that encourage entrepreneurs to found new ventures, and policies that encourage investors to fund new ventures. We distinguish between a short-term impact on current market activity, versus a long-term impact on future activity. Investing in entrepreneurial ventures requires tacit knowledge that is mainly acquired through prior entrepreneurial experience, implying that the supply of capital depends on successful entrepreneurs from prior generations. Recognizing this intergenerational linkage has a profound impact on the market equilibrium, and the effect of entrepreneurship policies. Our analysis identifies a rationale for using funding polices.
\end{abstract}

Keywords: Entrepreneurship, angel investors, start-ups, government policies, ecosystem, overlapping generations, steady state.

JEL classification: D53, D92, G28, L26.

*We would like thank Ashish Arora (the editor), three anonymous referees, Tom Astebro, Laurent Bach, Christian Catalini, Mike Devereux, Denis Gromb, Michel Habid, Thorsten Hens, Hans Hvide, Thorsten Martin, Ben Roin, Scott Stern, Per Strömberg, seminar participants at the University of Zurich, MIT Sloan School, University of Bergen, University of Oslo, Stockholm School of Economics, Hitotsubashi University, Keio University, University of Tokyo, and HEC Paris, and participants of the Macroeconomics of Entrepreneurship Conference in Montreal for their many helpful comments. Research assistance from Carolyn Hicks and Jiahui (Ryan) Zhuang is gratefully acknowledged. This research was supported by a research grant from the Social Sciences and Humanities Research Council (SSHRC).

${ }^{\dagger}$ University of Oxford, Saïd Business School, Park End Street, Oxford OX1 1HP, United Kingdom, e-mail: thomas.hellmann@sbs.ox.ac.uk.

\#Queen’s University, Smith School of Business, Goodes Hall, 143 Union Street, Kingston, Ontario, Canada K7L 3N6, e-mail: thiele@queensu.ca. 


\section{Introduction}

Policy makers across the globe want to foster their entrepreneurial ecosystems. Silicon Valley seems to be the envy of everyone, imitations abound: Silicon Forest (Oregon), Swamp (Florida), Gorge (UK), Glen (Scotland), Fjord (Norway), Wadi (Israel), Savannah (Kenya), and many more. The core reasons why policy makers want to promote entrepreneurship are fairly well understood, they relate mainly to economic growth, employment, and innovation (see Lerner (2008), Decker et al. (2014), Wilson (2015)). However, there are vast disparities in the approaches taken by governments to achieve these goals. The questions becomes how policy makers can foster entrepreneurship?

One common set of approaches focuses on expediting founding, facilitating entry into entrepreneurship, and promoting firm formation. Such policies come in a wide variety of forms, such as training, access to mentoring and expertise, or a reduction of bureaucratic red tape. In the US, the Small Business Administration (SBA) offers a large variety of training programs for entrepreneurs, and the I-Corps program of the National Science Foundation (NSF) provides entrepreneurship training for scientists and engineers. ${ }^{1}$ The website of the UK government alone lists over 250 business support programs for entrepreneurs. ${ }^{2}$ McKenzie and Woodruff (2014) summarize various studies on business support programs for entrepreneurs in developing countries.

A very different set of policies focuses on supporting the funding of entrepreneurial ventures. These policies use a variety of methods to encourage investors to channel more funding into start-ups. In the US, the SBIC program supports the funding of early-stage start-ups. According to the Angel Capital Association, more than half of all US states have some tax credits for angel investing. ${ }^{3}$ In the UK angel investors receive generous tax credits under the EIS/SEIS program. ${ }^{4}$ New Zealand has a government fund that matches private angel investments. ${ }^{5}$ Wilson and Silva (2013) provide a comprehensive discussion of government policies for early-stage funding across the OECD.

Applied policy analysis typically focuses on evaluating the effectiveness of specific programs in isolation. There is limited emphasis on contrasting policies, and asking what type of policies would be most effective. We therefore raise the fundamental question of how differ-

\footnotetext{
${ }^{1}$ See https://www.sba.gov/starting-managing-business and https://www.nsf.gov/news/special_reports/i-corps/

${ }^{2} \mathrm{https} / / / \mathrm{www} . g o v . u k /$ business-finance-support-finder/search?support_types $\% 5 \mathrm{~B} \% 5 \mathrm{D}=$ expertise-andadvice $\&$ postcode $=\&$ business_sizes $=\&$ sectors $=\&$ stages $=$

${ }^{3}$ See https://www.sba.gov/sbic and https://www.angelcapitalassociation.org/aca-public-policy-state-programdetails/

${ }^{4}$ https://www.gov.uk/government/publications/the-enterprise-investment-scheme-introduction

${ }^{5}$ See http://www.nzvif.co.nz/what-we-offer/seed-co-investment-fund and
} 
ent entrepreneurship policies compare in terms of their impact on entrepreneurial ecosystems. We tackle this question with a formal theory model that derives and contrasts the equilibrium impact of different government policies. Specifically we ask how different policies promote entrepreneurial activity, distinguishing between $(i)$ founding policies that affect what is often called the 'demand-side', i.e., the number of entrepreneurs demanding capital, versus $(i i)$ funding policies that affect the supply of funds to new ventures.

Based on a large prior entrepreneurial finance literature (see Da Rin et al. (2013)), we acknowledge that the financing of entrepreneurial ventures requires 'smart money'. Specifically it requires tacit knowledge about the entrepreneurial process that is mostly acquired by going through the entrepreneurial process itself. We view so-called 'angel' investing as the natural process by which experienced entrepreneurs pass on their knowledge to the next generation of entrepreneurs. In practice, the first check of successful start-ups often comes from angel investors who were successful entrepreneurs before: think of Andy Bechtolsheim, co-founder of Sun Microsystems, who wrote the first check for Google, or Peter Thiel, co-founder of PayPal, who wrote the first check for Facebook. In fact, over 70\% of all angels investing in Silicon Valley on AngelList, the leading US angel investment portal, have prior entrepreneurial experience (we discuss this more thoroughly in Section 3.1).

The importance of angel investors for the financing of early-stage ventures has also been established in the recent academic literature. Wilson (2011) estimates the total (visible and invisible) size of angel investments, and finds that the total amounts are approximately of the same order of magnitude as the total amounts invested in venture capital. Given that angel investments are much smaller, this means that many more start-ups receive angel financing than venture capital. Kerr et al. (2014) obtain data from US angel groups. Using a regression discontinuity approach, they identify the effect of angel investments on company performance. They find that angel investments lead to higher survival rates, better exits, more employment creation, higher patenting, and increased Web traffic. Lerner et al. (2018) expand that regression discontinuity approach to international data. They find evidence that is broadly consistent with Kerr et al. (2014), and also show that angel funding leads to more follow-on funding, such as from venture capitalists.

We use an 'overlapping generations' model to account for the accumulation of expertise in an entrepreneurial ecosystem. Early in their career entrepreneurs start new ventures that may succeed or fail. Successful entrepreneurs accumulate both the expertise and the wealth to then fund the next generation of entrepreneurs. This creates dynamic interlinkages between generations of entrepreneurs, where the supply of angel capital is a function of the number of 
past entrepreneurs and the wealth they accumulated. ${ }^{6}$ An important assumption is that angels are constrained in how much capital (beyond their own savings) they can leverage. This limits how much angels are able to pass on their skills and experiences to the next generation of entrepreneurs, and thus puts an upper bound on the availability of smart money in the ecosystem.

Promoting entrepreneurship is not a short-term endeavor. Silicon Valley took decades to become what it is today; its imitators had to learn how long it takes to create an entrepreneurial ecosystem (Lerner, 2008). Our dynamic model allows us to examine both the short-term and the long-term impacts of entrepreneurial policies. We first build a simple Walrasian model of the demand and supply for capital to fund new ventures, without any intergenerational linkages. We establish several important benchmark results. Comparable levels of founding and funding subsidies generate the same increase in entrepreneurial activity. However, founding policies create a competitive dynamic where more entrepreneurs seek a limited supply of funds, resulting in less favorable investment terms for entrepreneurs, i.e., lower valuations. By contrast, funding policies create a more abundant supply of capital which results in more favorable investment terms for entrepreneurs, i.e. higher valuations.

Next we introduce intergenerational linkages and show that the differences in valuations have important dynamic implications. This is because the wealth created by one generation of entrepreneurs determines the supply of angel capital for the next generation of entrepreneurs. One central result is that funding subsidies are more effective than founding subsidies for increasing entrepreneurial activity. A key intuition is that a founding subsidy reduces entrepreneurs' (nonmonetary) investment upfront, but also generates smaller (monetary) returns in case of success. Put differently, with a funding subsidy entrepreneurs have more "skin in the game", which in case of success results in higher returns that can be reinvested in new ventures.

Our model generates some interesting predictions about the dynamic path of entrepreneurial ecosystems. While there is always a unique equilibrium in every period, the model with intergenerational linkages can have multiple steady state equilibria (to which the period equilibria converge to). In the low (high) steady state equilibrium the lack (abundance) of entrepreneurial activity prevents (enables) the formation of angel capital for future generations, thus perpetuating the low (high) level of entrepreneurial activity. We show that even in the high steady state equilibrium there is too little entrepreneurial activity relative to the first best outcome. This is because future entrepreneurs benefit from the wealth of earlier generations, but this intergener-

\footnotetext{
${ }^{6}$ The following quote from Frédéric Mazzella, founder of BlaBlaCar (France's first start-up to achieve unicorn status) illustrates this core mechanism: "When you are an angel investor your value is not necessarily in the money but more in the access and experience you can provide to the inexperienced entrepreneur [...] I think it's important as a successful founder to re-invest in companies when you can, because it allows better knowledge transfer to the next generation." (Atomico, 2016, p. 59)
} 
ational externality is not taken into account by current investors. In the low equilibrium there is an additional rationale for government support, namely to provide temporary subsidies to lift the ecosystem above a critical threshold, beyond which there is a self-sustaining dynamic path toward the high equilibrium.

In our model funding subsidies are the optimal policy, but they can be implemented in several ways. One of them is to subsidize investments (such as an investment tax credit), another is to subsidize returns (such as a relief from capital gains taxation). Across several model extensions we find that the main results about the relative benefit of funding over founding policies continues to hold. However, we note that beyond the formal model, there may be reasons why founding policies may sometimes be preferable, such as if they are cheaper for the government to implement.

We extensively discuss the implications from our model for entrepreneurship policies, looking first at how policies affect a single ecosystem in isolation, and then looking at 'open ecosystem' issues that allow for capital mobility across ecosystems. We also provide an extensive discussion of how our analysis can guide future theoretical and empirical work.

Our paper relates to a diverse set of prior literatures. There is a large literature discussing differences in entrepreneurship across ecosystems, starting with the seminal work by Saxenian (1994); Lerner and Schoar (2010) contains a more recent overview. In terms of theory, the closest work are formal entrepreneurship theories with multiple equilibria, such as Canidio and Legros (2015) and Landier (2006). In terms of theories that examine how government policies affect entrepreneurs and investors, seminal contributions include Poterba (1989a, 1989b), and the work of Keuschnigg and Nielsen $(2003,2004)$. More recent contributions include Di Maio et al. (2016) and Egger and Keuschnigg (2015). None of these paper focus on the comparison of founding versus funding policies. ${ }^{7}$

A large prior literature looks at the dynamics of entrepreneurship. One important strand looks at the origin of entrepreneurial activities in terms of spin-offs from established companies. Relevant theories include Cassiman and Ueda (2006), Hellmann and Perotti (2011), and Rauch (2015). Important empirical works include Agarwal et al. (2004), Gompers et al. (2005), and Klepper and Sleeper (2005). Another strand looks at the role of serial entrepreneurs, including the work of Hsu (2007), Gompers et al. (2010), and Lafontaine and Shaw (2016). Axelson and Martinovic (2015) suggest that differences in the experience of entrepreneurs and investors can explain most of the differences in venture capital between Europe and the US. Our dynamic analysis also bears some resemblance to the dynamic innovation literature, such as the seminal

\footnotetext{
${ }^{7}$ In this context it is also worth mentioning a recent paper by Färnstrand Damsgaard et al. (2016), who provide both a theory and then some empirical evidence about a trade-off between R\&D versus commercialization policies.
} 
work by Green and Scotchmer (1995), that looks at sequential innovation, or the work by Arora et al. (2017), Gans (2017), and Segal and Whinston (2007), that looks at dynamic interactions between entrants and incumbents. Our specific interest here is a slightly different dynamic transition that has received less attention, namely the transition from entrepreneur to angel investor. The recent empirical explorations of Guiso et al. (2015) and Cumming et al. (2016) are a useful step in that direction. As a background, the work of Van Osnabrugge and Robinson (2000) and Wilson (2011) provide useful overviews of angel investing.

There is a growing policy literature on the merits of entrepreneurship policies. Lerner (2008) and Audretsch et al. (2007) provide extensive coverage of this topic, including a discussion of the pitfalls of misguided policies. Wilson and Silva (2013) and Wilson (2015) summarize a large body of research about the experience of OECD countries with entrepreneurship policies. The work of Leleux and Surlemont (2003) and Brander et al. (2015) empirically evaluates one important class of funding programs, namely government-supported venture capital. Our paper is also related to the broader literature on innovation and agglomeration, see Delgado et al. (2010), Ellison et al. (2010), and Glaeser et al. (2010), as well as the descriptive work of Startup Genome (2017).

Last but not least, our model suggests a societal benefit to having wealthy entrepreneurs, and a benefit of giving tax credits to 'already-rich' angel investors. At first sight this argument runs contrary to Piketty's (2014) warning about wealth inequality. However, our model does not suggest a blanket tax-exemption for the rich. Instead our argument is to create effective channels for rich entrepreneurs to reinvest their wealth (and their expertise) into the next generation of poor entrepreneurs. As such our argument focuses on creating a channel for social mobility. This argument is related to the recent work of Aghion et al. (2015) concerning the broader relationship between innovation and top income inequality.

We explain our theory in Section 2. Section 3 provides an extensive discussion of the implications of the model. It is followed by a brief conclusion. All proofs are in the Online Appendix, which is available on the authors' websites. 


\section{Main Model}

\subsection{Base Assumptions}

Consider an overlapping generations model where all parties are risk-neutral. ${ }^{8}$ In each period $t$ there is a continuous unit mass of potential entrepreneurs that are considering starting a new venture. Entrepreneurs have no initial wealth and face a non-monetary entry cost denoted by $l$ (see Jovanovic (1982)). For simplicity assume that $l$ has a uniform distribution over the interval $[0,1]{ }^{9}$ The number of entrepreneurs actually starting a venture in period $t$ is a continuous measure denoted by $n_{E, t}$; whenever possible we simply write $n_{E}$.

Each entrepreneur lives for three periods. In period 1, she starts a new ventures; we describe the main properties below. If the venture is successful, the entrepreneur has some wealth that she can invest in period 2. In period 3 she consumes the returns of all her investments. ${ }^{10}$

In period 1 the entrepreneur observes a business opportunity, and requires a fixed amount $\phi>0$ to start a venture. The project is good with probability $\gamma$, and bad with probability $1-\gamma$. A good project succeeds with probability $\rho$, generating a payoff $y>0$, and fails with probability $1-\rho$, generating a zero payoff. A bad project always fails and generates a zero payoff. In case of failure the entrepreneur has no more wealth, and plays no further role in the model. Ex-ante the entrepreneur does not know the quality of the project. In the absence of any signal about the project quality, the expected return from the venture is negative (formally $\gamma \rho y-\phi<0$ ). This implies that any general investors without a quality signal would loose money on average. Financing therefore requires some type of 'smart' investors. ${ }^{11}$.

We use the simplest possible model of smart investors where are two types of investors. Smart investors have the ability to observe whether the project is good or bad. Other 'not-sosmart' investors cannot distinguish good from bad projects, and therefore refrain from investing altogether. Amongst themselves, smart investors can pool their money, a process commonly known as syndication. For simplicity the base model does not allow 'not-so-smart' investors to

\footnotetext{
${ }^{8}$ In the Online Appendix we use a general time discount factor $\delta \in(0,1]$. However, in order to simplify the exposition in the main text we set $\delta=1$. Nothing depends on this simplification.

${ }^{9}$ In the Online Appendix we allow for a general uniform distribution over the interval $\left[0, \mu_{E}\right]$. However, to simplify the exposition in the main text we conveniently assume $\mu_{E}=1$. Nothing depends on this assumption.

${ }^{10} \mathrm{We}$ relax this time structure in Section 3.2 which looks at the possibility that angels and entrepreneurs operate over multiple periods.

${ }^{11}$ It is straightforward to extend the model by allowing for imperfect screening. Suppose, for example, that each angel gets a public binary signal about the quality of a given project. If the underlying project is good, the signal is always good, but if the underlying project is bad, then the smart investor gets a negative signal with probability $\chi$, and a positive signal with probability $1-\chi$. In case all smart investors receive the same signal, i.e., their signals are perfectly correlated, we can simply write the success probability of a project with a positive signal as $\rho=\frac{\gamma}{\gamma+(1-\gamma)(1-\chi)}$.
} 
join smart syndicates, but Section 3.1 shows that this assumption is easily relaxed. We call the market for funding the 'angel market'. For simplicity we assume perfectly competitive pricing. A syndicate of investors receives an equity stake $\alpha$ in return for providing the capital $\phi$.

In our base model we assume that only those angel investors who were formerly successful entrepreneurs (period 1) can observe the quality of a project (smart investors). The number of investors who have both the funds and the skills to invest in new ventures is thus given by $\gamma \rho n_{E, t-1}$. The wealth of these investors is endogenously determined by their ownership in their prior entrepreneurial ventures, and therefore given by $\left(1-\alpha_{t-1}\right) y$.

In period 2 a formerly successful entrepreneur can invest her wealth $\left(1-\alpha_{t-1}\right) y$. First, we assume there is a safe asset that generates a safe return of $1 .{ }^{12}$ Second, there is the possibility of investing in the next generation of entrepreneurs. We call an investor an angel whenever the investor chooses to invest in an entrepreneurial venture. We denote the amount of angel investing by $k$ so that an investor invests $k \in\left[0,\left(1-\alpha_{t-1}\right) y\right]$ in new ventures, and invests the remaining $\left(1-\alpha_{t-1}\right) y-k$ in the safe asset. We assume that angel investing involves some private costs. These can be thought of as legal and due diligence costs, the opportunity cost of time, and the personal preferences for engaging in angel investing. Specifically we assume that each successful entrepreneur has a monetary cost $\theta k$ of making angel investments, where $\theta$ is drawn from a uniform distribution over the interval $[0,1] \cdot{ }^{13}$ For our base model we use a proportional cost specification, but all of the results of the base model continue to hold if instead we assumed a fixed cost of making angel investments. ${ }^{14}$

Central to our argument is that angel investing requires special skills that cannot be taken for granted in an ecosystem. ${ }^{15}$ The most natural source for acquiring such skills is to go through the entrepreneurial experience itself, and then use the experience, as well as the acquired wealth, to fund the next generation of entrepreneurs. Note that it is the combination of entrepreneurial experience and wealth that creates entrepreneurial angels. Unsuccessful entrepreneurs may or may not have useful skills, but they lack the wealth to become angel investors in this model.

\footnotetext{
${ }^{12}$ As mentioned above, the Online Appendix uses a time discount factor of $\delta$. The safe asset then generates the return $1+r$, where $r=\frac{1-\delta}{\delta}$.

${ }^{13}$ In the Online Appendix we allow for a general uniform distribution over the interval $\left[0, \mu_{I}\right]$. Again, to simplify the exposition in the main text we set $\mu_{I}=1$. Nothing depends on this assumption.

${ }^{14}$ In a proportional cost model, we associate investor costs with some costs of allocating funds to risky angel investments. In a fixed cost model we associate investor costs with some costs of setting up the overall angel portfolio. A priori we do not have a strong opinion which one is more relevant, and in fact we might expect them to coexist in reality. The reason why we use a proportional cost specification is that it generates simpler mathematical expressions. The proofs for the model with fixed costs are available from the authors upon request.

${ }^{15}$ As a stylistic note, we use the term 'ecosystem' where many economists might use the term 'economy'. The meanings are very close, although the term 'ecosystem' is meant to clarify that entrepreneurship is only one part of the overall economy.
} 
In our base model we only consider entrepreneurial angels who succeeded within the same ecosystem. This allows us to focus on the endogenous determination of an angel market. In Section 3.3 we also allow for external angels from other entrepreneurial ecosystems (such as Silicon Valley).

\subsection{Benchmark Model Without Intergenerational Dynamics}

As a building block it is useful to consider a model without intergenerational dynamics, i.e., without entrepreneurial angels. For this we temporarily assume that the number of smart angels is exogenously given by $\widetilde{n}$, and their individual wealth is exogenously given by $\widetilde{w}$.

Consider the optimal investment decision of investors. In exchange for investing the amount $\phi$ in a venture with a good project, investors receive an ownership stake $\alpha$, which generates the expected return $\rho \alpha y$. From the perspective of an individual investor this means that investing the amount $k$ in good ventures generates an expected return of $\frac{k}{\phi} \alpha \rho y$. The remaining wealth $\widetilde{w}-k$ can then be invested in the safe asset, generating a unit return. The expected utility of an investor is thus given by

$$
U_{I}(k)=\frac{k}{\phi} \alpha \rho y-\theta k+(\widetilde{w}-k) .
$$

We note that $U_{I}(k)$ is linear in $k$, so there exists a critical investment cost $\widehat{\theta}$, such that for $\theta \leq \widehat{\theta}$ it is optimal for the investor to invest the entire wealth in new ventures $\left(k^{*}=\widetilde{w}\right)$, and for

$\theta>\widehat{\theta}$ it is optimal to invest the entire wealth in the safe asset $\left(k^{*}=0\right)$. The threshold is given by $\widehat{\theta}=\alpha \frac{\rho y}{\phi}-1$, which is an increasing function of the ownership share $\alpha$, and the venture's net economic return $\frac{\rho y}{\phi}$. The aggregate supply of angel capital is thus given by $\widehat{\theta} \widetilde{n} \widetilde{w}$.

Now consider the demand for capital from entrepreneurs that are entering the market. An entrepreneur's expected utility of starting a venture (with unknown project quality) is given by $U_{E}=\gamma \rho(1-\alpha) y$. This has to be traded off against the cost of entry $l$. Clearly, entry is optimal as long as $U_{E} \geq l$, so that the number of entrepreneurs (which is a continuous measure) is given by

$$
n_{E}=U_{E}=\gamma \rho(1-\alpha) y
$$

We call this the entry condition.

The total amount of capital that all entrepreneurs with good projects demand is given by $\gamma n_{E} \phi$ (smart angels do not invest in bad projects). In equilibrium this must be equal to the total 


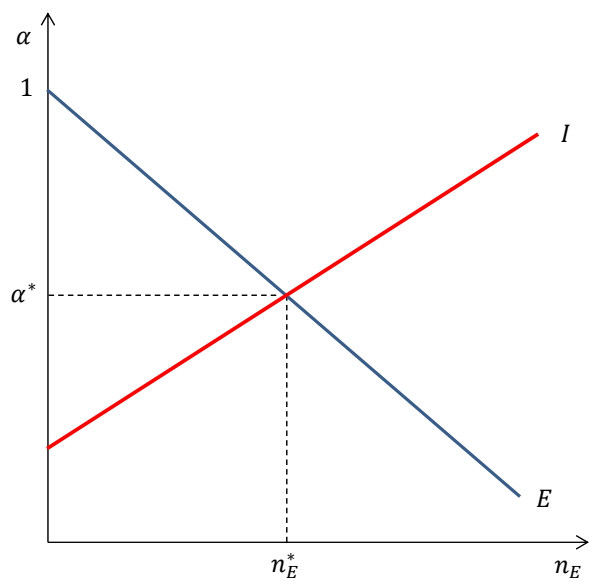

Figure 1: Benchmark Model - Market Equilibrium

capital supply, so that $\gamma n_{E} \phi=\widehat{\theta} \widetilde{n} \widetilde{w}$. Using the entry condition (1) and the definition of the critical investment cost $\widehat{\theta}$, we can write the market clearing condition as

$$
\gamma^{2} \rho(1-\alpha) y \phi=\left(\alpha \frac{\rho y}{\phi}-1\right) \widetilde{n} \widetilde{w}
$$

This defines the equilibrium equity stake for investors, $\alpha^{*}$, with $\alpha^{*} \in\left[\frac{\phi}{\rho y}, 1\right]$. The market equilibrium $\left\{n_{E}^{*}\left(\alpha^{*}\right), \alpha^{*}\right\}$ is therefore fully characterized by the entry condition (1) and the market clearing condition (2). ${ }^{16}$

Consider Figure 1. On the vertical axis we put $\alpha$, a measure of investor ownership and thus the effective price of capital. On the horizontal axis we put $n_{E}$, the relevant quantity variable, namely the number entrepreneurs seeking financing for their projects. The demand curve is downward sloping, because fewer entrepreneurs want to enter with a higher price of capital (i.e., higher $\alpha$ ). The supply curve is upward sloping, because more investors want to invest in the angel market when the net returns are higher. ${ }^{17}$

The comparative statics of the market equilibrium are very intuitive. The equilibrium level of entrepreneurial activity $n_{E}^{*}$ is increasing in the probability of success $\rho$, the payoff $y$, the number of angels $\widetilde{n}$, and their levels of wealth $\widetilde{w}$; it is decreasing in the required amount of

\footnotetext{
${ }^{16}$ Note that the total capital demand, $E(\alpha) \equiv \gamma^{2} \rho(1-\alpha) y \phi$, is decreasing in $\alpha$, while the total capital supply from investors, $I(\alpha) \equiv\left[\alpha \frac{\rho y}{\phi}-1\right] \widetilde{n} \widetilde{w}$, is increasing in $\alpha$. Moreover, note that $E\left(\frac{\phi}{\rho y}\right)>I\left(\frac{\phi}{\rho y}\right)=0$, and $I(1)>E(1)=0$. This implies that the market equilibrium is unique.

${ }^{17} \mathrm{We}$ can also interpret Figure 1 using the concept of valuation. The so-called post-money valuation of a venture investment is defined as $\phi / \alpha$, so that a higher $\alpha$ corresponds to a lower valuation. Entrepreneurs prefer higher valuations, investors prefer lower valuations. As $\alpha$ increases, entrepreneurs' utilities decrease and the demand slopes downwards, but investor's utilities increase and the supply slopes upwards.
} 
capital $\phi$. The investor's ownership stake $\alpha^{*}$ is increasing in $\phi$ and $\gamma$, and it is decreasing in $\widetilde{n}$, $\widetilde{w}, \rho$, and $y$.

To examine whether the market equilibrium is efficient, we compare it with the first best equilibrium that maximizes the sum of all utilities (i.e., the total expected utility of all entrepreneurs and investors).

Proposition 1 Without intergenerational dynamics, the competitive equilibrium is socially efficient.

The equilibrium in the benchmark model is efficient, because it is a standard competitive Walrasian model with no externalities. Even though there is no rationale for government intervention, it is still instructive to look at the effects of two alternative types of government subsidies (we discuss the interpretation of theses subsidies in Section 3). The first subsidy targets the demand side by subsidizing founding, the second subsidy targets the supply side by subsidizing funding. We take the total available government budget as given, and ask which policy is more effective in fostering entrepreneurship.

We define a founding subsidy as an in-kind support to potential entrepreneurs that want to start a venture. The subsidy specifically reduces the non-monetary cost of entry by $S_{E}$, which implies that entry is now optimal as long as $U_{E} \geq l-S_{E} \cdot{ }^{18}$ The entry subsidy $S_{E}$ affects the entry and market clearing conditions as follows:

$$
\begin{aligned}
n_{E} & =\gamma \rho(1-\alpha) y+S_{E} \\
\gamma\left[\gamma \rho(1-\alpha) y+S_{E}\right] \phi & =\left[\alpha \frac{\rho y}{\phi}-1\right] \widetilde{n} \widetilde{w} .
\end{aligned}
$$

We see from the entry condition (3) that founding subsidies have a direct and positive effect on entry. This in turn increases the demand for capital, as can be seen from the market clearing condition (4). This affects $\alpha$, the equilibrium equity stake for investors.

Next, we define a funding subsidy as a financial support to potential investors that want to invest in new ventures with good projects. For now we consider a simple tax-credit of $s_{I}$ for every unit of investment. This means that when investing $k$, an angel receives a total tax credit of $k s_{I} \cdot{ }^{19}$ Section 2.6 also looks at alternative funding policies.

\footnotetext{
${ }^{18} \mathrm{We}$ assume that the government cannot discriminate among entrepreneurs with different values of $l$, so that all entrepreneurs that want to enter can take advantage of the subsidy. Moreover, in the case of $l<S_{E}$ we simply assume that the entrants' cost of entry remains zero, but that the government still pays the full cost.

${ }^{19}$ Again we assume that the government cannot discriminate among investors with different values of $\theta$, so that all investors receive the same subsidy.
} 
Unlike a founding subsidy $S_{E}$ that is given to all projects, a funding subsidy only applies to good projects, i.e., to those that pass the investor screen. For our policy comparison it is useful to define $S_{I} \equiv \gamma \phi s_{I}$ as the expected funding subsidy per firm. This ensures that the government's overall payouts under the two policies are the same whenever $S_{E}=S_{I}{ }^{20}$

With a funding subsidy $S_{I}$ the market equilibrium is characterized by the following entry and market clearing conditions:

$$
\begin{aligned}
n_{E} & =\gamma \rho(1-\alpha) y \\
\gamma^{2} \rho(1-\alpha) y \phi & =\left[\alpha \frac{\rho y}{\phi}-1+\frac{1}{\phi} \frac{1}{\gamma} S_{I}\right] \widetilde{n} \widetilde{w} .
\end{aligned}
$$

A funding subsidy increases the supply of angel capital, thereby directly affecting the equilibrium investor stake $\alpha^{*}$. Through $\alpha^{*}$, it indirectly affects the equilibrium number of entrepreneurs $\left(n_{E}^{*}\right)$, as can be seen from the entry condition (5).

Providing a subsidy naturally has a cost in the ecosystem, which we can think of as the cost of raising distortionary taxes. To keep our analysis focused on the relative merits of founding versus funding subsidies, we refrain from modeling the government's overall maximization problem of what level of subsidies to provide. Instead we consider a small fixed government budget, and ask how it can be applied to either a founding subsidy $S_{E}$ or a funding subsidy $S_{I}$. We begin by stating a useful benchmark results concerning the effects of demand-side versus supply-side polices.

Proposition 2 Consider the benchmark model without intergenerational dynamics.

(ii) The effect of a demand-side founding subsidy $\left(S_{E}\right)$ is to increase the equilibrium number of entrepreneurs $\left(n_{E}^{*}\right)$, and to increase the investor's ownership stake $\left(\alpha^{*}\right)$.

(iii) The effect of a supply-side funding subsidy $\left(S_{I}\right)$ is to increase the equilibrium number of entrepreneurs $\left(n_{E}^{*}\right)$, and to decrease the investor's ownership stake $\left(\alpha^{*}\right)$.

(iv) Equivalent levels of founding and funding subsidies $\left(S_{E}=S_{I}\right)$ result in equivalent equilibrium numbers of entrepreneurs $\left(n_{E}^{*}\left(S_{E}\right)=n_{E}^{*}\left(S_{I}\right)\right)$, but with different ownership $\operatorname{stakes}\left(\alpha^{*}\left(S_{E}\right)>\alpha^{*}\left(S_{I}\right)\right)$.

\footnotetext{
${ }^{20}$ For example, suppose there are 1,000 new ventures, of which 800 have good projects $(\gamma=0.8)$. If the government's budget is $\$ 1 M$, then the (expected) founding subsidy is simply $S_{E}=\$ 1,000$. This is received by all 1,000 firms, thus costing the government $\$ 1 M$. The combined funding subsidy given to all angels investing in a single firm with a good project, is $\phi s_{I}=\$ 1,250$. Overall there are 800 good firms, so that the total cost for the government is again $\$ 1 M$. The expected funding subsidy for all firms (with good and bad projects) is given by $S_{I}=\gamma \phi s_{I}=0.8 * 1,250=\$ 1000$.
} 

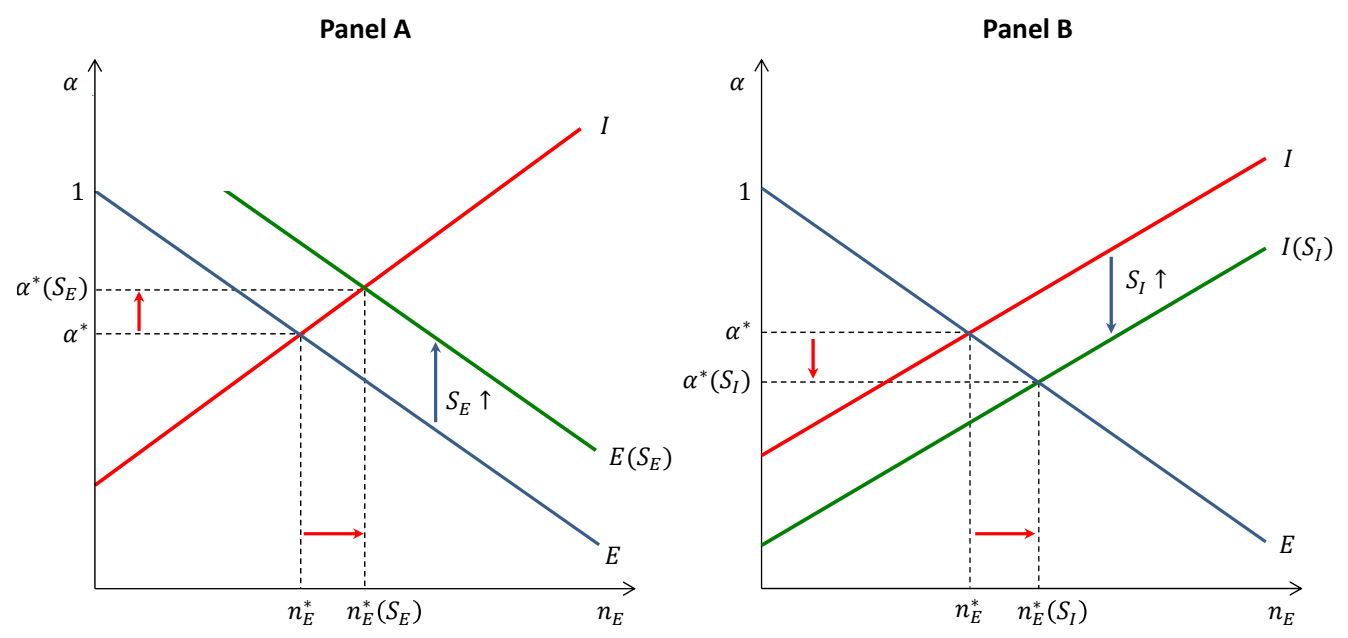

Figure 2: Benchmark Model - Effect of Subsidies

Figure 2 accompanies Proposition 2, showing in Panel A the effect of a founding policies $\left(S_{E}\right)$, and in Panel B the effect of funding policy $\left(S_{I}\right)$. We can see that both policies are effective in raising the equilibrium level of entrepreneurial activity: founding subsidies by shifting the demand curve, and funding subsidies by shifting the supply curve.

An important finding is that the two policies create different equilibrium investment terms. Founding policies create relatively more favorable terms for investors, as they lead to relatively higher ownership stakes $\alpha^{*}$ (i.e., lower valuations). At first glance one might have expected that funding policies would be more favorable for investors, because investors receive a subsidy. However, our equilibrium analysis suggests an interesting countervailing mechanism. With a founding subsidy, more entrepreneurs enter the market and seek funding. This creates a competitive dynamic where entrepreneurs bid up the stakes they are willing to give to investors in exchange for funding. Hence the benefit of the subsidy is partly offset by lower valuations, i.e., higher equity stakes for investors.

The last part of Proposition 2 states that comparable subsidy levels $\left(S_{E}=S_{I}\right)$ generate identical levels of entrepreneurial activity $\left(n_{E}^{*}\left(S_{E}\right)=n_{E}^{*}\left(S_{I}\right)\right)$. However, the mechanisms behind founding and funding subsidies are fundamentally different, as the former affect the non-monetary cost of entering the market for entrepreneurs, whereas the latter affect the investment terms obtained after entering the market. In fact, in the Online Appendix we show that in equilibrium angels have the same expected wealth at the end of the period, irrespective of whether they receive the monetary funding subsidy or not. However, entrepreneurs end up with a higher expected wealth under the (monetary) funding subsidy than the (non-monetary) 
founding subsidy. Most important, we will now see that this 'equivalence result' only applies to the benchmark model, but will not be true in our main model with intergenerational dynamics.

\subsection{Model With Intergenerational Dynamics}

In this section we add intergenerational dynamics by introducing entrepreneurial angels. Specifically, we allow successful entrepreneurs to invest their wealth into the next generation of entrepreneurs.

An important change in the model with entrepreneurial angels concerns the expected utility of becoming an entrepreneur, which now includes not only the returns from the entrepreneurial activity itself, but also the returns from future angel investing. Specifically, a successful entrepreneur will bring $\left(1-\alpha_{t}\right) y$ of wealth into the next period. She can then invest her wealth either in new ventures or in the safe asset. As long as her individual investment $\operatorname{cost} \theta$ in the next period $(t+1)$ is sufficiently low $\left(\theta \leq \widehat{\theta}_{t+1}\right)$, it is optimal for the entrepreneur to invest the entire wealth $\left(1-\alpha_{t}\right) y$ in new ventures. The discounted net return from the angel investments is given by $\left(\alpha_{t+1} \frac{\rho y}{\phi}-\theta\right)\left(1-\alpha_{t}\right) y$. Otherwise, if her investment cost is too high $\left(\theta>\widehat{\theta}_{t+1}\right)$, she invests her entire wealth in the safe asset, which yields the net return $\left(1-\alpha_{t}\right) y$. At time $t$, the realization of $\theta$ is still unknown, so the expected utility of an entrepreneur at time $t$ is

$$
U_{E, t}=\gamma \rho\left[\int_{0}^{\widehat{\theta}_{t+1}}\left(\alpha_{t+1} \frac{\rho y}{\phi}-\theta\right)\left(1-\alpha_{t}\right) y d \theta+\int_{\widehat{\theta}_{t+1}}^{1}\left(1-\alpha_{t}\right) y d \theta\right]
$$

where $\widehat{\theta}_{t+1}=\alpha_{t+1} \frac{\rho y}{\phi}-1$.

The entry condition for entrepreneurs is then given by

$$
n_{E, t}=U_{E, t}
$$

An important element of the intergenerational model is that the number of angels depends on the number of successful entrepreneurs from the previous period $\left(\gamma \rho n_{E, t-1}\right)$. Formally, the number of entrepreneurial angels actually investing in new ventures in period $t$ is given by $\widehat{\theta}_{t} \gamma \rho n_{E, t-1}$. Each of these angels invests the amount $\left(1-\alpha_{t-1}\right) y$. The market clearing condition is thus given by

$$
\gamma n_{E, t} \phi=\left[\alpha_{t} \frac{\rho y}{\phi}-1\right] \gamma \rho n_{E, t-1}\left(1-\alpha_{t-1}\right) y .
$$

In each period, the intergenerational model has a unique equilibrium that is defined by the entry condition (7) and the market clearing condition (8). We can see from (7) in conjunction 
Panel A

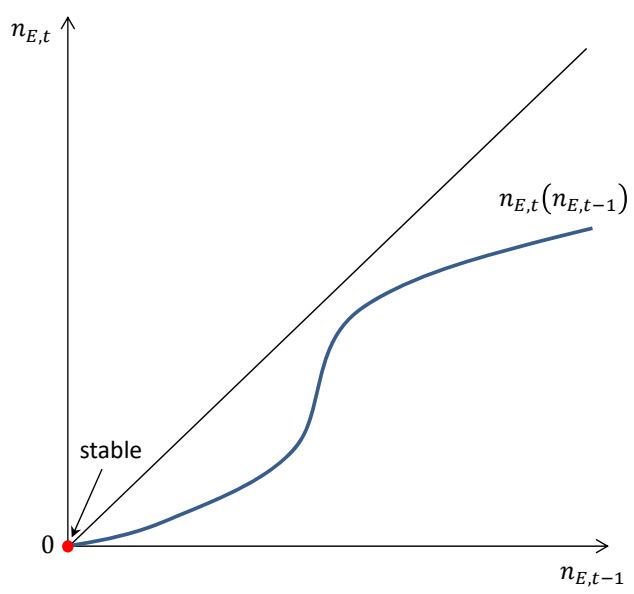

Panel B

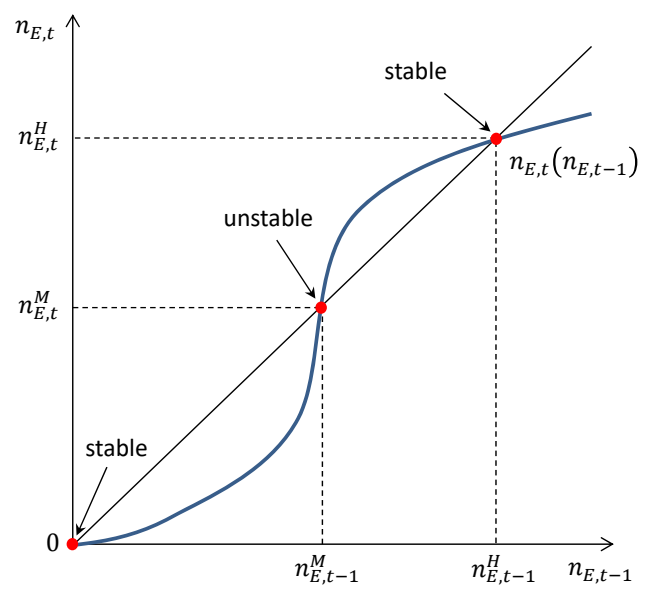

Figure 3: Dynamic Model - Equilibria

with (8) that entrepreneurial entry in the previous period $\left(n_{E, t-1}\right)$ affects the present equilibrium equity stake for investors $\left(\alpha_{t}\right)$, and therefore the present entry of entrepreneurs $\left(n_{E, t}\right)$.

Even though each period has a unique equilibrium, there may be multiple steady state equilibria to which the period equilibrium converges to. We show this formally in the Online Appendix. For the main text we refer to Figure 3, which illustrates the dynamic evolution of the key state variable $n_{E, t}^{*}$ from one period to the next. Specifically, the S-shaped curve in Figure 3 shows how $n_{E, t}^{*}$ depends on $n_{E, t-1}^{*}$. It starts at the origin, and has a strictly positive slope. Intuitively, more entrepreneurial activity in the previous period creates a larger pool of potential angels, which results in a higher level of entrepreneurial activity in the current period. However, the slope of the curve varies and may be less than 1, suggesting that a unit increase in the past activity may result in less than a unit increase in the current period.

In a steady state we have $n_{E, t}^{*}=n_{E, t-1}^{*}$; this is where the $\mathrm{S}$-curve intersects the 45 degree line, as shown in Figure 3. Clearly, this always happens at the origin where $n_{E, t}^{*}=n_{E, t-1}^{*}=0$. The question is whether there are further intersections so that $n_{E, t}^{*}=n_{E, t-1}^{*}>0$. This happens in Panel B of Figure 3, but not in Panel A. In the Online Appendix we formally show that there exists a critical investment level $\widehat{\phi} \in(0, \rho y)$ such that for $\phi>\widehat{\phi}$ only the low steady state equilibrium $n_{E, t}^{*}=n_{E, t-1}^{*}=0$ exists (as shown in Panel A), but for $\phi<\widehat{\phi}$ three steady state equilibria exist (as shown in Panel B). Moreover, standard dynamic analysis reveals that the lowest and the highest equilibria are stable, while the middle one is unstable. We can therefore focus on the low and high equilibrium. ${ }^{21}$

\footnotetext{
${ }^{21}$ For $\phi=\widehat{\phi}$ two equilibria exist, the low one is stable, the high one unstable. In the Online Appendix we further show that given uniform distributions for $l$ and $\theta$, the maximum number of equilibria is three.
} 
Panel A

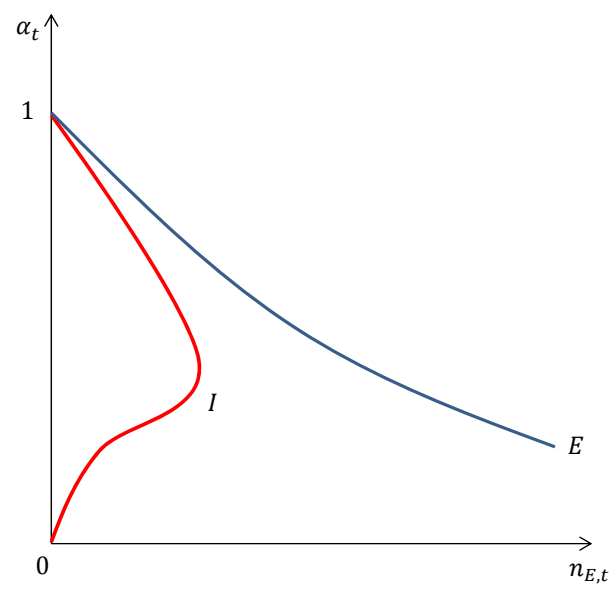

Panel B

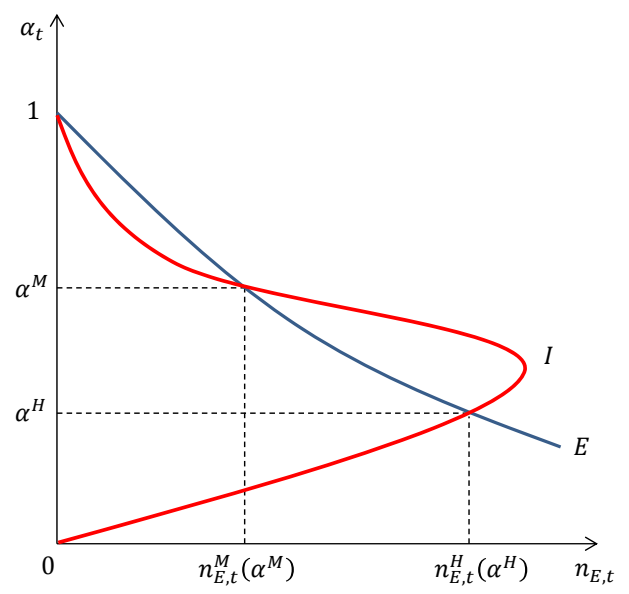

Figure 4: Dynamic Model - Capital Supply and Demand

To better understand the structure of these equilibria, consider Figure 4 which illustrates steady state demand and supply functions. Even though the entrepreneur's utility function $U_{E, t}$ is now more complicated, as it includes the returns to angel investing, we show in the Online Appendix that the demand function continues to be downward sloping. The supply function $(I)$, however, becomes non-monotonic. Initially it is upward sloping for the same reason that it is upward sloping in Figure 1, namely that higher returns induce angels to invest more. However, there is an important countervailing effect that becomes dominant for larger values of $\alpha$. Giving investors a higher equity share also means leaving entrepreneurs with a lower share. This has no effect on the total wealth available for investments in a model without intergenerational linkages. With such linkages, however, it means that entrepreneurial angels have less wealth to invest. That is, a higher share for investors means better returns to current angel investors, but also less wealth for future angel investors. The second effect can dominate, thus causing the supply curve to bend backwards. Indeed, as $\alpha$ approaches 1 , the supply curve falls back to zero. This is for the simple reason that at $\alpha=1$, even successful entrepreneurs have no wealth, and therefore have nothing to invest.

Panel A of Figure 4 shows the case of $\phi>\widehat{\phi}$, and Panel B the case of $\phi<\widehat{\phi}$. The difference between Panel A and Panel B is that in Panel A the supply curve begins to slope backwards relatively early, before ever intersecting with the demand curve. In this case the only equilibrium is the low equilibrium, as depicted in Panel A of Figure 3. In Panel B the supply 
curve intersects the demand curve before sloping down again. This is what creates the three equilibria depicted in Panel B of Figure $3 .^{22}$

\subsection{The Effect of Government Subsidies}

Before looking at the effects of founding and funding subsidies in the model with intergenerational dynamics, we ask whether there is indeed a role for the government to intervene in the market. For this we compare the high steady state equilibrium (denoted by $\left\{n_{E}^{*} ; \alpha^{*}\right\}$ ) with the first best equilibrium (denoted by $\left\{n_{E}^{f b} ; \alpha^{f b}\right\}$ ) that maximizes the steady state sum of all expected utilities (i.e., total welfare).

Proposition 3 The high steady state equilibrium does not maximize welfare, because it has too few entrepreneurial ventures (i.e., $n_{E}^{*}<n_{E}^{f b}$ ), and investors get too much equity (i.e., $\alpha^{*}>\alpha^{f b}$ ).

Proposition 3 shows that the competitive equilibrium is not first best. The underlying reason is that there is an intergenerational externality. Entrepreneurs and angel investor take into account their contemporaneous utilities, and entrepreneurs take into account the future utility of potentially becoming an angel investor, but no one takes into account the utility of future entrepreneurs. Future entrepreneurs need experienced angel investors, and therefore rely on the wealth creation of past generations of entrepreneurs. We find that relative to the first best level, there is insufficient entrepreneurial wealth creation. Investors get too much equity, and successful entrepreneurs have too little wealth for reinvesting in the next generation of entrepreneurs. This result provides a rationale for government action (provided the cost of any intervention is not too high).

Consider first the effects of a founding subsidy $S_{E}$. We treat this as a non-monetary subsidy that makes it easier for entrepreneurs to start a new venture. The effect of the subsidy is to reduce the costs of entry, i.e., the effective cost of entry becomes $l-S_{E}$. For now we focus on

\footnotetext{
${ }^{22}$ The intuition for why the existence of a high equilibrium requires lower capital needs $\phi$ can be obtained from Figure 3. For a given number of old entrepreneurs $\left(n_{E, t-1}\right)$, lower values of $\phi$ permit a greater number of new entrepreneurs $\left(n_{E, t}\right)$ to be funded. This means that in Figure 3 lower values of $\phi$ lift the S-curve up. In Figure 4, this gets translated into a leftward shift of the supply curve, again representing a greater number of new entrepreneurs $\left(n_{E, t}\right)$. It follows that multiple equilibria can only exist for sufficiently low values of $\phi$, as shown in Panel B of Figures 3 and 4.
} 
the high steady state equilibrium (where $n_{E, t}=n_{E, t-1}$ and $\alpha_{t}=\alpha_{t-1}$ ), which is defined by the following conditions:

$$
\begin{aligned}
n_{E} & =U_{E}+S_{E} \\
\phi & =\left(\alpha \frac{\rho y}{\phi}-1\right) \rho(1-\alpha) y
\end{aligned}
$$

where

$$
U_{E}=\gamma \rho\left[\int_{0}^{\widehat{\theta}_{t+1}}\left(\alpha_{t+1} \frac{\rho y}{\phi}-\theta\right)(1-\alpha) y d \theta+\int_{\widehat{\theta}_{t+1}}^{1}(1-\alpha) y d \theta\right]
$$

The level of entrepreneurial activity, $n_{E}^{*}$, is defined by the entry condition (9). The equilibrium equity stake for investors, $\alpha^{*}$, is characterized by the market clearing condition (10).

Proposition 4 The effect of a founding subsidy $S_{E}$ in the high steady state equilibrium is to increase the level of entrepreneurial activity (i.e., $d n_{E}^{*}\left(S_{E}\right) / d S_{E}>0$ ). However, there is no effect on the equilibrium ownership stake (i.e., $\left.d \alpha^{*}\left(S_{E}\right) / d S_{E}=0\right)$.

The first part of Proposition 4 is intuitive: founding subsidies lower barriers to entry and therefore encourage more entrepreneurs to start new ventures, as can be seen from the entry condition (9). This corresponds to an upward shift of the demand curve. In the model with intergenerational linkages, more entry also increases the number of successful entrepreneurs that become angel investors. This causes the supply curve to shift upwards, which further increases the equilibrium level of entrepreneurial activity. In equilibrium the demand and supply effect reinforce each other and create a robust positive effect on the level of entrepreneurial activity.

The second part of Proposition 4 about constant ownership stakes contrasts with the findings from the model without intergenerational linkages, where founding subsidies were associated with higher ownership stakes (i.e., lower valuations). To make sense of this we note that the equilibrium ownership stake for investors, $\alpha^{*}$, is determined by the ratio of entrepreneurs to angels in the market. The equilibrium ownership stake can only change if this ratio changes. We know from Proposition 4 that a founding subsidy $S_{E}$ encourages more entrepreneurs to enter, and this leads to more angel investors in the next period. In the high steady state equilibrium it turns out that the increase in the number of entrepreneurs is followed by a proportional increase 
in the number of angel investors. This leaves the equilibrium ratio of entrepreneurs to investors unaffected, and thus the ownership stake $\alpha^{*}$ does not change. ${ }^{23}$

Next we consider the effects of a funding subsidy $S_{I}$ on the high steady state equilibrium, which is defined by the following entry and market clearing conditions:

$$
\begin{aligned}
n_{E} & =U_{E}\left(S_{I}\right) \\
\phi & =\left(\alpha \frac{\rho y}{\phi}-1+\frac{1}{\phi} \frac{1}{\gamma} S_{I}\right) \rho(1-\alpha) y,
\end{aligned}
$$

where

$$
U_{E}\left(S_{I}\right)=\gamma \rho\left[\int_{0}^{\widehat{\theta}_{t+1}+\frac{1}{\phi} \frac{1}{\gamma} S_{I}}\left(\alpha_{t+1} \frac{\rho y}{\phi}+\frac{1}{\phi} \frac{1}{\gamma} S_{I}-\theta\right)(1-\alpha) y d \theta+\int_{\widehat{\theta}_{t+1}+\frac{1}{\phi} \frac{1}{\gamma} S_{I}}^{1}(1-\alpha) y d \theta\right] .
$$

In the model with intergenerational dynamics, a funding subsidy $S_{I}$ does not only affect the capital supply (as in our benchmark model), but also the expected utility of an entrepreneur, $U_{E}\left(S_{I}\right)$, and therefore the overall level of entrepreneurial activity, $n_{E}^{*}$. Specifically, we can see from the entry condition (11) that a funding subsidy increases the expected returns from angel investment. This increases the threshold cost $\widehat{\theta}_{t+1}+\frac{1}{\phi} \frac{1}{\gamma} S_{I}$, and thus increases the marginal incentive to invest in new ventures as opposed to the safe asset.

Proposition 5 The effect of a funding subsidy $S_{I}$ in the high steady state equilibrium is to increase the level of entrepreneurial activity (i.e., $d n_{E}^{*}\left(S_{I}\right) / d S_{I}>0$ ). In addition, it decreases the equilibrium ownership stake (i.e., $\left.d \alpha^{*}\left(S_{I}\right) / d S_{I}<0\right)$.

Proposition 5 shows that funding policies again increase the level of entrepreneurial activity. They clearly shift the supply curve upwards as the subsidy increases the net return to angel investing. They also shift the demand curve. Entry becomes more attractive not only because of a lower $\alpha$ (which represents a movement along the demand curve), but also because the subsidy increases the rewards to being a successful entrepreneur, who use the subsidies once becoming an angel investor. Again the demand and supply effect reinforce each other to increase the equilibrium level of entrepreneurial activity.

Unlike in Proposition 4, however, there is an effect on equilibrium ownership stakes, which is reduced by higher subsidies. This is in line with the findings from Proposition 2. Specifically,

\footnotetext{
${ }^{23}$ This particular result depends on the assumption of no external angels. Once we allow for some external angels (see Section 2.5), the ratio of entrepreneurs to angels changes with $S_{E}$, and we find again that ownership shares for investors increase with founding subsidies, i.e., $d \alpha^{*}\left(S_{E}\right) / d S_{E}>0$.
} 
funding subsidies encourage more potential angel investors to actually invest in new ventures, as reflected by the threshold value $\widehat{\theta}+\frac{1}{\phi} \frac{1}{\gamma} S_{I}$. This increases the number of active angels relative to the number of entrepreneurs, and therefore results in lower equilibrium ownership stakes for angel investors.

We are finally in a position to address the key question of how the two policies compare.

Proposition 6 Consider a founding and a funding subsidy at equivalent levels of subsidization, so that $S_{E}=S_{I}>0$. In the high steady state the funding subsidy generates a higher level of entrepreneurial activity than the founding subsidy, i.e., $n_{E}^{*}\left(S_{I}\right)>n_{E}^{*}\left(S_{E}\right)$. It also generates a lower level of investor ownership, i.e., $\alpha^{*}\left(S_{I}\right)<\alpha^{*}\left(S_{E}\right)$.

Proposition 6 stands in sharp contrast to Proposition 2 where we found that the two policies did not generate different levels of entrepreneurial activities. This is no longer true in the presence of intergenerational linkages. Funding subsidies generate a higher level of entrepreneurial activity than founding subsidies, precisely because of their long-term intergenerational impact. Funding policies ultimately benefit entrepreneurs by increasing valuations (i.e., lowering $\alpha$ ). Having entrepreneurs retaining larger ownership stakes increases the amount of wealth that they can invest in the next generation of entrepreneurs. Moreover, a funding subsidy encourages more successful entrepreneurs to invest their wealth into entrepreneurial ventures, as opposed to the safe asset. This creates a virtuous cycle that permanently increases entrepreneurial activity.

\subsection{Catalyst Government Policies}

So far we examined how permanent government policies affect entrepreneurship in the high steady state equilibrium. However, an ecosystem may not necessarily be in the high equilibrium. In this section we briefly show how temporary subsidies can be used to help an ecosystem to move towards the high steady state equilibrium.

Let us consider an ecosystem that has some level of entrepreneurship, but it is below the unstable middle equilibrium $n_{E}^{M}$, as shown in Panel B of Figure 3. Standard dynamic analysis reveals that, in the absence of any government policies, an ecosystem converges to the high (low) equilibrium whenever the current level of activity $n_{E, t}$ lies above (below) the critical threshold $n_{E}^{M}$. Now suppose the government is looking for a temporary subsidy to push the ecosystem above the critical level $n_{E}^{M}$, in order to set it onto a path towards the high equilibrium $\left(n_{E}^{H}\right) .{ }^{24}$ Specifically, suppose the government offers a one-time subsidy $S_{E, t}$ (founding subsidy)

\footnotetext{
${ }^{24}$ Strictly speaking, the economy can be below $n_{E}^{M}$, but it needs to be above the zero equilibrium. This is for the simple reason that in the zero equilibrium there are no entrepreneurs that can be subsidized. Once we introduce
} 
or $S_{I, t}$ (funding subsidy) in period $t$. For parsimony we derive the new equilibrium conditions in the Online Appendix; here we simply state our main finding:

Proposition 7 Compared to a temporary founding subsidy $\left(S_{E, t}\right)$, an equivalent temporary funding subsidy $\left(S_{I, t}\right)$ leads to more entrepreneurship in period t as well as in all subsequent periods. Formally, for $S_{I, t}=S_{E, t}$, we find that $n_{E, t+i}^{*}\left(S_{I, t}\right)>n_{E, t+i}^{*}\left(S_{E, t}\right)$ for all $i=0,1, \ldots, \infty$.

The key difference between a temporary founding or funding subsidy is their dynamic effect on future market outcomes. Proposition 2 implies that a funding subsidy creates wealthier entrepreneurs that have more to invest in the next generation of entrepreneurs. ${ }^{25}$ It is therefore easy to see that a temporary funding policy advances the ecosystem further towards the high steady state equilibrium than a founding policy. The key insight is that what matters is not only increasing the current level of entrepreneurial activity, but also increasing the amount of wealth available to future entrepreneurial angels. Consequently we find that the same logic that made funding subsidies powerful in the high steady state equilibrium, also applies to catalyst policies for pushing the ecosystem towards the high equilibrium. Note, however, that the high steady state equilibrium itself is not affected by a temporary subsidy, as the eventual point of convergence remains the same for both types of subsidy.

\subsection{On the Optimality of Funding Subsidies}

Our main model focuses on two prominent classes of entrepreneurship policies: those targeted at encouraging entrepreneurial entry, and those targeted at facilitating the financing of entrepreneurial ventures. This allows us to identify the key economic properties of demand-based versus supply-based policy approaches within a dynamic entrepreneurial ecosystem. Empirically, there are many different types of entrepreneurship policies used by governments around the globe; we discuss this further in Section 3. From a theory perspective, the question is whether funding policies are always optimal within the current model.

We assume that the government can only offer non-discriminatory policies, i.e., it cannot offer differential subsidies to different entrepreneurs or angel investors. In the Online Appendix we formally show that in our model a funding subsidy is an optimal subsidy. We first show that relative to a founding subsidy, a funding subsidy achieves not only higher activity levels, but also higher levels of social welfare (as measured by the sum of all utilities). We then show that

external angels, there are always some entrepreneurs (see Section 3.3), and this technical requirement becomes irrelevant.

${ }^{25}$ In the Online Appendix we formally show that this effect on the expected wealth of entrepreneur, remains true in the model with catalyst policies; see Proof of Proposition 7. 
within the constraints of our model, there are no other subsidies that can achieve higher social welfare levels for a given government budget. ${ }^{26}$

There is one interesting twist to this argument. So far we have expressed funding subsidies in terms of investment subsidies. We now go one step further and show that we could also think of funding policies as return subsidies. That is, in our model funding subsidies are optimal, but they can be implemented either as investment subsidies, or as return subsidies. Let us explain.

Return subsidies affect the payoff $(y)$ from a venture in case of success. Capital gains reliefs are a prominent example for this class of subsidies: Many governments offer some kind of preferential treatment for capital gains from entrepreneurial ventures; the US Small Business Jobs Act of 2010 is a recent example. Similarly, corporate tax rates and other business taxes can also affect the returns to entrepreneurial ventures.

To model the effect of return subsidies, suppose the government can provide direct or indirect support that increases the returns of a venture from $y$ to $y+\tau$. We note that entrepreneurs and investors only benefit from this subsidy when their ventures succeed. From an ex-ante perspective, the discounted expected value from the return subsidy is given by $S_{R}=\gamma \rho \tau$, so that each new venture with a good project generates the expected payoff $y+\frac{S_{R}}{\gamma \rho}$.

In the Online Appendix we derive the new equilibrium conditions, and obtain the following three main results about the properties of return subsidies. First, for the benchmark model without dynamic linkages, we find that larger return subsidies lead to more entry $\left(d n_{E}^{*}\left(S_{R}\right) / d S_{R}>\right.$ 0 ) and lower ownership stakes for investors $\left(d \alpha^{*}\left(S_{R}\right) / d S_{R}<0\right)$. Moreover, we extend the equivalence result from Proposition 2 by showing that return subsidies achieve the same level of entrepreneurial activity as comparable founding or funding subsidies (i.e., $n_{E}^{*}\left(S_{R}\right)=n_{E}^{*}\left(S_{E}\right)=$ $n_{E}^{*}\left(S_{I}\right)$ for all $\left.S_{R}=S_{E}=S_{I}\right)$. Second, we show that larger return subsidies also increase entry and decrease ownership stakes in the dynamic model with intergenerational linkages. Finally we show that return and funding subsidies have in fact identical properties, in the sense that equivalent subsidy levels $\left(S_{R}=S_{I}\right)$ generate the same equilibrium level of entrepreneurial activity $\left(n_{E}^{*}\left(S_{R}\right)=n_{E}^{*}\left(S_{I}\right)\right)$, and even the same expected level of entrepreneurial wealth. The reason for this last result is that both policies create the same expected net value for an entrepreneurial venture with a good project, as given by $\rho y-\phi+S_{R}+S_{I}$. The equilibrium allocation of this net value between the entrepreneur and investor is then determined by the same underlying market forces, irrespective of whether funding or return subsidies are used. ${ }^{27}$

\footnotetext{
${ }^{26}$ Our sparse model set-up naturally limits the set of potential government policies; in reality governments can call upon a much richer set of policies. We discuss this further in Section 3.

${ }^{27}$ Finally we briefly note that the equivalence of funding subsidies $\left(S_{I}\right)$ and return subsidies $\left(S_{R}\right)$ can be further expanded using the well-established 'tax incidence equivalence' (TIE) result. This says that the burden of a tax (or subsidy) on buyers and sellers is independent of who nominally pays the tax (or receives the subsidy). In the
} 


\section{Model Extensions}

\subsection{Experience and Capital}

For our base specification we used the simplest possible investor model, where the only smart investors are formerly successful entrepreneurs. Only they can observe whether the project is good or bad. Other 'not so smart' investors can't, and therefore never invest. Clearly this model is highly stylized, so it might be useful to briefly reiterate its purpose. Our core argument is that financing entrepreneurs requires 'experienced capital'. A prior literature (see Da Rin et al. (2013)) richly documents the notion that investing in start-ups requires an active investment style by capable investors. The novel part of our argument is that this capability derives from a prior experience of being a successful entrepreneur. This is what gives rise to the intergenerational dynamics that drive our new results.

Given the centrality of investor experience in our model, let us provide some preliminary empirical evidence about the experience of angel investors. We gathered data from AngelList, the leading US angel investment online platform. Among other things it allows investors to post their profile. ${ }^{28}$ In July 2017 we downloaded the profiles of angel investors who declared an interest to invest in three parts of the US: (i) Silicon Valley, the most important entrepreneurial ecosystem in the world, (ii) Florida, a state with a large number of wealthy individuals, and (iii) North Carolina, which contains the research triangle, an important technology cluster. ${ }^{29}$ We then identify whether these angels had previously founded any companies. Based on this we classified angels into two categories, those with and those without prior entrepreneurial experience. Using additional web searches we also verified that their prior companies can be legitimately considered start-ups, and not investment vehicles or charitable organizations. Table 1 shows our main findings.

For Silicon Valley we find that $71.9 \%$ of all angels are angels with prior entrepreneurial experience. In Florida it is $46.8 \%$, and for North Carolina it is $36.4 \%$. Interestingly, angels with prior entrepreneurial experience make on average more investments in startup companies: $74.1 \%$ of all investments in Silicon Valley are made by entrepreneurial angels, $68.3 \%$ in Florida, and $68.2 \%$ in North Carolina. Moreover, in Silicon Valley the average number of start-ups that

Online Appendix we show how the usual TIE result applies in our context. In particular, it does not matter whether the funding subsidy $S_{I}$ is given to the investor or the entrepreneur. This is because the nominal 'price' $\alpha$ readjusts to generate the same real price, irrespective of who nominally receives the subsidy.

${ }^{28}$ See URL: https://angel.co/people/all

${ }^{29}$ On AngelList there were in total 2,690 profiles of angels interested to invest in Silicon Valley, 370 in Florida, and 151 in North Carolina. However, for Silicon Valley, AngelList only allowed to access the profiles of 587 angels (likely due to some download restrictions). 


\begin{tabular}{|c|c|c|c|c|c|c|}
\hline & \multicolumn{2}{|c|}{ SILICON VALLEY } & \multicolumn{2}{|c|}{ FLORIDA } & \multicolumn{2}{|c|}{ NORTH CAROLINA } \\
\hline & $\begin{array}{l}\text { Entrepreneurial } \\
\text { angels }\end{array}$ & $\begin{array}{c}\text { Non-entrepreneurial } \\
\text { angels }\end{array}$ & $\begin{array}{l}\text { Entrepreneurial } \\
\text { angels }\end{array}$ & $\begin{array}{c}\text { Non-entrepreneurial } \\
\text { angels }\end{array}$ & $\begin{array}{l}\text { Entrepreneurial } \\
\text { angels }\end{array}$ & $\begin{array}{c}\text { Non-entrepreneurial } \\
\text { angels }\end{array}$ \\
\hline Percentage of angels & $71.9 \%$ & $28.1 \%$ & $46.8 \%$ & $53.2 \%$ & $36.4 \%$ & $63.6 \%$ \\
\hline $\begin{array}{l}\text { Percentage of start-up } \\
\text { investments }\end{array}$ & $74.1 \%$ & $25.9 \%$ & $68.3 \%$ & $31.7 \%$ & $68.2 \%$ & $31.8 \%$ \\
\hline $\begin{array}{l}\text { Average (median) number } \\
\text { of start-up investments made }\end{array}$ & $34.6(25)$ & $30.9(24)$ & $6.3(2)$ & $1.3(0)$ & $9.1(3)$ & $2.4(1)$ \\
\hline $\begin{array}{l}\text { Average (median) number } \\
\text { of start-ups founded }\end{array}$ & $2.2(2)$ & $0(0)$ & $2.2(2)$ & $0(0)$ & $1.9(2)$ & $0(0)$ \\
\hline
\end{tabular}

Table 1: Prior Entrepreneurial Experience (AngelList)

entrepreneurial angels have founded, is 2.2 (median of 2), suggesting that many angels have substantial entrepreneurial experience. The averages for Florida and North Carolina are close by, at 2.2 and 1.9 (both with median of 2). ${ }^{30}$

Overall this preliminary data supports our core assumption that experienced entrepreneurs play a central role in angel markets. At the same time it also raises some additional challenges for the theory. Many but not all angel investors are experienced entrepreneurs. This would suggest that our model ought to be robust to adding some smart investors that are not formerly successful entrepreneurs. From a theory perspective, this means that in addition to the endogenously determined entrepreneurial angels, there can also be exogenous angels active in the market. In the Online Appendix we derive such a model extensions. The main notable difference is that the low equilibrium now has a positive level of investments and entrepreneurs. ${ }^{31}$

A second challenge for the theory is that other 'not so smart' investors are not necessarily excluded from the angel market. Let us motivate this point with another observation from AngelList. In addition to allowing companies and investors to list their information on the website, AngelList also has a 'Syndicates' function that enables crowdfunding through its platform. Syndicates are structured around a lead investor who commits to providing a certain amount of core funding. Other investors can then join the syndicate through a simple online investment process. Agrawal et al. (2016) empirically investigate these syndicates and show how they

\footnotetext{
${ }^{30}$ Another interesting piece of evidence comes from a survey of European entrepreneurs, which finds that $44 \%$ of experienced repeat entrepreneurs make angel investments (Atomico, 2016, p. 59). This report also notes the rise of founder-led funds, quoting Philipp Magin, founder of Quandoo and cofounder of CityDeal/Group: "Yes, there is an emergence of founder-led funds. The reason for this seems to be pretty clear - founders aim to invest proceeds from previous successful entrepreneurial activities in the area where they have high expertise, and institutional as well as private or corporate investors trust their experience-based assessment and join as LPs." (Atomico, 2016, p. $60)$.

${ }^{31}$ The model with some exogenous angels is technically the same as the small open ecosystems model discussed in Section 3.3.
} 
allow reputable angel investors to leverage their investments with funding from a crowd of less experienced investors. Other equity crowdfunding websites, such as SyndicateRoom in the UK, also offer similar investment structures for crowd investors.

All this suggests that general investors might be able to ride on the coattails of smart investors. Modeling the micro-foundations of how smart and other investors interact is beyond the scope of this paper (see Admati and Pfleiderer, 1994, Casamatta and Haritchabalet, 2007, Kremer, 1998). We use a simple 'reduced form' approach to model how 'not so smart' investors can join the investments of smart investors. Suppose again that only smart investors can identify companies with good projects, but suppose now that they can leverage their investments with capital from other investors. For simplicity we assume that smart investors need to provide a minimum amount of capital $\omega \phi$ (where $\omega \in(0,1)$ ). This can now be topped up with $(1-\omega) \phi$ of 'not so smart' capital, which we assume can be supplied at will. We maintain the assumption that $\omega>0$, because smart investors need to have some incentives to properly identify good companies, and to provide some value-adding support (Da Rin et al., 2013). In the Online Appendix we rederive the market equilibrium and establish the following two main insights.

First, the smaller $\omega$, the larger the total angel market. This is simply because a smaller $\omega$ allows for a bigger leverage of other capital. This suggests that leveraging other investors has a positive effect on the level of entrepreneurship. The crowdfunding syndicate structure analyzed by Agrawal et al. (2016), for example, should therefore help to increase the size of the angel market. Second, the main results from Propositions 1-6 continue to hold for all values of $\omega$. While 'not so smart' capital increases the size of the market, the comparative statics of the model, including all the policy results, depend on the intergenerational linkages, and are not affected by $\omega$.

\subsection{Serial Investors and Entrepreneurs}

In this section we examine the implications of angels being able to invest over multiple periods, what we call serial angel investing. Part of our motivation here is to look for boundary conditions of our main policy result. One conjecture is that serial angel investments can reverse our main result that funding policies foster more entrepreneurship than founding policies in the long-term. The intuition is that if angels invest over longer periods, then there might be a benefit to having wealthy angels rather than wealthy entrepreneurs. However, it turns out that this intuition is incorrect.

In the Online Appendix we provide a model extension where at the end of each period investors continue for another period with some probability $\sigma_{I}$, and retire with probability $\left(1-\sigma_{I}\right)$. 
This implies a Markov process where investors invest on average for $1 / \sigma_{I}$ periods. ${ }^{32}$ Again we first consider a benchmark model without intergenerational transitions. Serial angels increase the overall level of entrepreneurship by increasing the supply of capital. However, even with serial angels, the equivalence result of Proposition 2 continues to hold. This is because a founding subsidy generates a higher investor stake $\alpha$, but a funding subsidy directly increases investor returns at a given $\alpha$. In the model with intergenerational linkages and serial investors we also find that our main results continue to hold. Overall we note that adding serial investors does not change our core results.

The model extension in the Online Appendix also allows for serial entrepreneurs. Again we use a Markov model where after each period entrepreneurs can start another company with some probability $\sigma_{E}$, and otherwise transition to the angel stage. Serial entrepreneurs do not need to re-incur the fixed costs. The Online Appendix shows that all of our main results about the effects of subsidies remain intact. Yet another model variation looks at the possibility that some entrepreneurs grow their companies, instead of exiting at the end of the first period. This is sometimes called the scale-up stage, i.e., the growth stage that comes after the start-up stage. ${ }^{33}$ Formally, with probability $\xi$ a successful entrepreneur has a growth option to increase the value of the company. We show that having more entrepreneurs with the option to grow their companies, leads more entrepreneurs and angels in the steady state equilibrium, as well as lower equity shares for investors.

\subsection{Open Ecosystems}

Our main model considers a single ecosystem in isolation; we now examine how capital may flow from one ecosystem to another. ${ }^{34}$ While a complete formal derivation of all the properties of the dynamic equilibria is beyond the scope of this paper, we briefly discuss how the model can be extended to allow for capital flows across ecosystems. For this we focus at a model where capital moves from a large to a small ecosystem. ${ }^{35}$ Similar to a 'small open economy'

\footnotetext{
${ }^{32}$ One technical detail worth mentioning is that in order to solve the Markov model with serial angel investing we need stationarity. While we noted that the base model can be solved either with proportional or fixed investors costs, this particular model extension can only be solved with proportional costs, as this is the only way of generating a stationary Markov process.

${ }^{33}$ See Duruflé et al (2018).

${ }^{34}$ Relatively little is known about cross-border angel investing, but the empirical evidence on venture capital suggests that foreign investors play a considerable role in many less developed markets (see Aizenman and Kendall (2012)). An interesting case study is Israel (Avnimelech et al. (2005), Senor and Singer (2009)) which explicitly attracted foreign investors, mostly from the US, to jump-start its entrepreneurial ecosystem.

${ }^{35}$ Our analysis here focuses on capital flows between ecosystems. A related issue is labor mobility of entrepreneurs, often referred to as brain drain. This is clearly a complex phenomenon, and its analysis is beyond the scope of this paper.
} 
Panel A

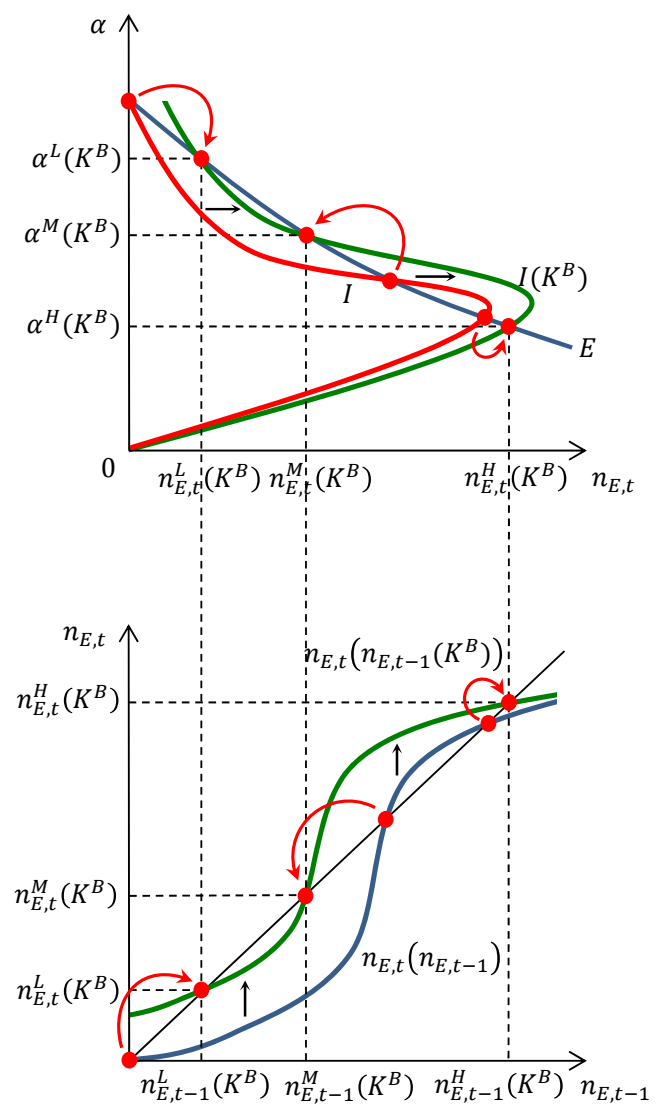

Panel B
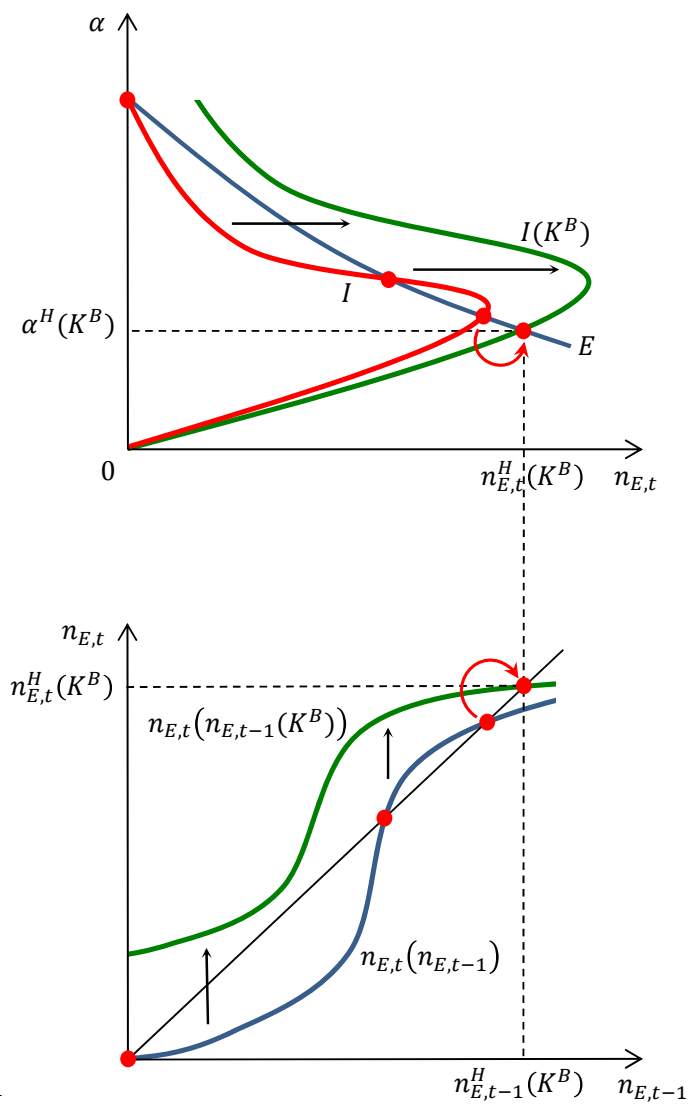

Figure 5: Equilibria with Foreign Angels

in the international trade literature, we look at the effect of a large system on a small system, without worrying about any reverse effects. Such a model captures the situation of many regions with smaller ecosystems that want to tap into Silicon Valley, as mentioned in the Introduction. Consider two countries, called $A$ and $B$. Suppose that the entrepreneurial ecosystem in $A$ is relatively small compared to $B$ 's, and assume that $A(B)$ is in a low (high) equilibrium. We know from Section 2.3 that investors get a relatively higher ownership stake $\alpha$ in the low equilibrium. This encourages foreign investors from country $B$ to invest in $A$. Thus, capital always flows from $B$ to $A$. Suppose there are $\widetilde{n}$ investors in $B$, each with wealth $\widetilde{w}$, who consider to invest in $A$. They face a distance $\operatorname{cost} \lambda>0$ for every unit of capital invested abroad. The total flow of capital from $B$ to $A$ is given by $K^{B}=(\widehat{\theta}-\lambda) \widetilde{n} \widetilde{w}$. Adding this to the usual domestic supply of capital, we rederive the equilibrium in the Online Appendix. In the main text we use a graphical approach. 
Figure 5 illustrates the effects of foreign angel capital $K^{B}$ flowing into country $A$. This shifts up the supply curve but does not affect demand. Panel $A$ shows a small infusion of foreign capital. In the steady state equilibrium we find that this leads to higher entry levels $\left(n_{E}^{*}\right)$ and lower ownership stakes $\left(\alpha^{*}\right)$. The low equilibrium continues to exist, but is no longer fixed at the origin (i.e., $n_{E}^{*}>0$ ). In equilibrium some investors are foreign, others are domestic. The latter are successful domestic entrepreneurs from the prior generation, many of whom were themselves funded by foreign investors.

Panel B of Figure 5 shows the effect of a larger infusion of foreign capital $K^{B}$. Once the supply curve shifts sufficiently, the low steady state equilibrium disappears. This generates some interesting dynamics. Initially the majority of deals is funded by foreign investors. They create some successful domestic entrepreneurs who invest into the next generation of entrepreneurs. Over time the foreign investors are increasingly joined by domestic entrepreneurial angels. As the ecosystem moves towards the high equilibrium, the fraction of ventures funded by foreign angels decreases. This is because there are more domestic entrepreneurial angels, and because over time valuations in $A$ increase, making country $A$ less attractive to foreign investors. As $A$ approaches the high equilibrium, foreign investors no longer play a role, since all entrepreneurs in $A$ are funded by home-grown entrepreneurial angels.

How do founding and funding policies interact with foreign capital? The Online Appendix shows that all the results from the base model continue to apply. ${ }^{36}$ An interesting question is whether the funding subsidy should be given only to domestic investors or also to foreign investors. Our model suggests that it should be given to both, for the simple reason that not giving it to foreign investors would limit the supply of the much needed capital. This is particularly true near the low steady state equilibrium, where the majority of funding comes from foreign investors. In practice governments may be reluctant to hand out subsidies to foreigners. The key insight from this model is that 'experienced' foreign money helps to build domestic experience, and therefore has a positive externality on the domestic ecosystem.

So far our analysis assumes that the quality of ventures is the same in the two ecosystems. A prior literature on entrepreneurial ecosystems (see Kenney (2000) and Lee et al. (2000)) suggests that ecosystems have multiple feedback loops that help to improve the quality of ventures. While our model emphasizes dynamic externalities, this literature emphasizes 'cross-sectional' externalities, i.e., externalities across firms, as well as between firms, investors, and other service providers. Formally modelling this is beyond the scope of this paper, but it is useful to

\footnotetext{
${ }^{36}$ One noteworthy difference is that the slight counter-intuitive finding in Proposition 4 that $d \alpha^{*}\left(S_{E}\right) / d S_{E}=0$ no longer applies. Once we allow for some foreign angels we find again that ownership increases with founding subsidies, i.e., $d \alpha^{*}\left(S_{E}\right) / d S_{E}>0$.
} 
briefly consider a simple 'reduced form' version where project quality is increasing in the level of entrepreneurial activity $\left(n_{E}^{*}\right)$. Our model has two important project quality parameters: the probability that an idea is good $(\gamma)$, and, for a good idea, the probability of success $(\rho) .{ }^{37}$ The key difference between these two parameters is that the uncertainty about $\gamma$ gets resolved prior to financing, whereas the uncertainty around $\rho$ only gets resolved after financing.

Consider first the case where $\gamma$ is an increasing function of $n_{E}$. In the low steady state equilibrium, low values of $\gamma$ discourage the demand but not the supply of capital. Specifically, on the demand side a low value of $\gamma$ discourages entry, because potential entrepreneurs realize that it is rare to get a good project that is fundable. Yet on the supply side $\gamma$ does not matter, because investors have the ability of distinguish good from bad projects. ${ }^{38}$ Things are more complicated when $\rho$ is an increasing function of $n_{E}$. Of particular note is the case of $\rho\left(n_{E}=0\right)<\phi / y$, so that all projects have negative expected returns in the low equilibrium. In this case it becomes harder to escape the low equilibrium trap, because no foreign investor wants to invest. One way out is a large government subsidy $\left(S_{I}\right)$ that absorbs all the losses from investing in ventures with negative expected returns. Interestingly, a founding subsidy $\left(S_{E}\right)$ would not work at all in this case. This is because even if a generous subsidy $S_{E}$ convinces entrepreneurs to enter, there are no investors willing to finance their projects. Overall we note that 'cross-sectional' externalities further reinforce the relative advantage of funding over founding policies.

\section{Model Implications}

\subsection{Implications for Entrepreneurship Policy}

This paper raises some fundamental questions about entrepreneurship policies. In this section we discuss some of the broader implications. Our analysis emphasizes the dynamic aspect of entrepreneurship policies, and the process by which ecosystems are built over time. This approach contrasts with parts of the ecosystems literature which emphasizes the interaction between a diverse set of players, focusing on 'cross-sectional' rather than 'longitudinal' aspects of ecosystem development (see also our discussion in Section 3.3). The cross-sectional literature focuses on the interplay between entrepreneurs, different types of investors, universities and research labs, established corporations, stock markets, supply chains, service providers, and so on. Our goal here is to add a dynamic component to the analysis. Specifically we argue

\footnotetext{
${ }^{37}$ The value of success $y$ plays a similar role as the probability of success $\rho$.

${ }^{38}$ This observation would change if we added investor screening costs, i.e., if the evaluation of projects was costly to investors. In this case, low values of $\gamma$ would discourage investments in a way similar to low values of $\rho$.
} 
that some of the critical components of an entrepreneurial ecosystem can only be grown over time. The underlying premise is that one of the required inputs for building entrepreneurial ventures is a type of tacit knowledge that can only be acquired through direct experience of the entrepreneurial process. The key novelty of our analysis is the intergenerational linkage: the fact that younger generations of entrepreneurs benefit from the experience of previous generations, and the fact that over a career, individuals switch from being the key promoter (the entrepreneur), to being a key input provider (the investor).

Our dynamic perspective of looking at the accumulation of expertise has immediate policy implications. First and foremost, any short-term evaluation of entrepreneurship policies is fundamentally incomplete and possibly misguided. An evaluation of entrepreneurship policies requires a long-term perspective, and needs to focus on the accumulation of experience as a key metric. While this is immediately apparent in our model, we would argue that current practice is far off. Most entrepreneurship policies are measured either on the basis of how much entrepreneurial activity they encourage, or how successful that activity is. Concretely, most entrepreneurship programs are evaluated either in terms of direct inputs - how much money is invested in how many companies - or direct outputs - how many companies succeed, and how many jobs were created. Our dynamic perspective challenges these approaches by arguing that a key metric for evaluating entrepreneurship policies is how much they add to the stock of accumulated experience that can be leveraged by the next generation of entrepreneurs. Admittedly this poses a significant measurement challenge, as it requires data about the career paths of the individuals in the supported ventures, and how they contribute to the ecosystem after exiting from these ventures. ${ }^{39}$

One interesting finding in our model is that even the simplest specification of intergenerational linkages immediately generates multiple equilibria. This paper is by no means the first to recognize the possibility of multiple equilibria in the market between entrepreneurs and investors (see Michelacci and Suarez (2004) and Landier (2006)). The novelty here is that the multiplicity of equilibria does not stem from a standard coordination problem where one side of the market needs the other side to do something; instead it comes from the dynamics of how expertise is accumulated over time. To be precise, in our model there is actually a unique equilibrium in every period, and therefore no coordination problem. However, there can be multiple steady state equilibria to which the period equilibria converge to over time. Put differently, the

\footnotetext{
${ }^{39}$ To give an example, the full economic impact of PayPal concerns not only the company itself, but also the so-called 'PayPal mafia' - the people that came out of PayPal, and became involved with companies as diverse as Facebook, SpaceX, Airbnb, Uber, and others (see Forrest (2014)).
} 
challenge here is not to bring together different players to coordinate; the challenge here is to dynamically build sufficient expertise for the ecosystem to become self-sustaining.

This multiple equilibria result suggests different roles for governments in more versus less advanced ecosystems. In a high equilibrium there is a potential role for the government because of a fundamental intertemporal externality: future generations benefit from the entrepreneurial experiences of past generations. In a low equilibrium, there is an additional rationale for government support, namely to help the ecosystem move from the low to the high equilibrium. In the model we show that this requires lifting the ecosystem to a minimum threshold of entrepreneurial activity, to set it onto a self-sustaining dynamic upwards path. This calls for temporary government policies, where apart from the steady state logic of an intergenerational externality, there is a temporary catalytic logic for entrepreneurship policies. A practical challenge is that policy makers would need to identify where such a critical threshold might lie, and how to implement temporary policies that can be credibly phased out as the ecosystem moves onto a self-sustaining path.

This paper looks at the trade-off between two canonical classes of entrepreneurship policies: founding and funding policies. We focus on these two policies because they represent two important and distinct classes of entrepreneurship policies. Our model of founding subsidies is a stylized depiction of a large set of 'demand-side' policies, i.e., policies that encourage more entrepreneurial entry, and hence increase the 'demand' for capital. Across the globe there exist a large number of policies that encourage people to become entrepreneurs, consisting of a variety of skills training and mentoring services. Closely related, there are numerous policies for facilitating the initial steps of starting a business, such as business accelerators and incubation facilities. Another broad class of policies that fit our model of founding subsidies are commercialization grants that push technologies out of universities and other research institutions into the market. We contrast these demand-side founding subsidies with funding policies that encourage the supply of capital to entrepreneurial ventures. As discussed in Section 2.6, our funding subsidy can also be understood in terms of a return subsidy, such as capital gains holidays, or corporate income tax breaks. Despite its simplicity (or indeed because of it), our model captures a large swath of entrepreneurship policies.

The finding that funding policies ultimately benefit entrepreneurs more than founding policies, is not immediately obvious. One might have expected that demand-side subsidies are more favorable to entrepreneurs than supply-side subsidies, but this is why a proper equilibrium model is needed. Our analysis reveals a new and ultimately very simple logic that founding policies generate more entrepreneurs chasing money, whereas funding policies generate more investors chasing deals (see also Gompers and Lerner (2000), Hellmann and Thiele (2014), 
Inderst and Müller (2004)). An interesting question concerns the boundary conditions of this central result. What assumptions would be required for founding policies to become preferable over funding policies?

In Section 3.2 we already conjectured that varying the number of periods that angels and entrepreneurs can operate might reverse our main policy result, but actually found that this is not the case. Another conjecture is that relaxing the assumption of non-monetary founding subsidies might reverse our main result. In the Online Appendix we show that even if founding subsidies were monetary, it would still be true that the wealth of successful entrepreneurs is higher under a funding than a founding subsidy, so that again funding policies work better than founding policies. ${ }^{40}$

All this suggests that on the benefit side, funding policies dominate founding policies under most reasonable circumstances. However, the analysis so far assumes that the government faces the same costs for both policies. Founding policies may well become preferable to funding policies if they are cheaper to implement. This is ultimately an empirical question, but there are some reasonable arguments as to why funding policies might sometimes be more expensive than founding policies. For this we need to distinguish between two types of costs: program costs, and misallocation costs.

First, there are program cost of delivering subsidies. Funding policies are monetary transfers, so their costs include the monetary value of the subsidies, the government's marginal cost of funds (which takes into account distortionary costs of taxation), and the administrative costs of dispensing the subsidies. By contrast, we think of founding policies as non-monetary transfers. It is thus conceivable that a 'perceived' unit of subsidy has a lower cost for the government. This would happen, for example, if the government provides inexpensive training for entrepreneurs that helps them to overcome exaggerated fears of starting a company. In model terms, a unit reduction of the non-monetary entry barrier might cost the government less than a unit of monetary subsidies.

Second, there are misallocation costs. The idea is that in addition to attracting legitimate users, every subsidy also attracts some illegitimate users that somehow manage to satisfy the formal requirements, but do not meet the intended economic purpose. For example, in addition

\footnotetext{
${ }^{40}$ The Online Appendix further explores another model variant where both founding and funding subsidies are non-monetary. We show that under very special circumstances it is possible to obtain a reversal of our main policy result. Specifically, we show that a non-monetary funding policy can be inferior to a non-monetary founding policy, provided there are no intergenerational linkages, and provided angels can invest more than once (we show this for the simplest possible case where angels can invest exactly twice). In principle one could think of policies that encourage angel investments without providing any financing, such as free educational training for angels, but in practice such policies are rare. Moreover, this result only shows that these peculiar non-monetary funding subsidies are inferior. It still remains true that a monetary funding subsidy is superior to a founding subsidy.
} 
to being used for genuine start-ups, a funding subsidy might be used for dishonest ventures that effectively tunnel the money away. We would argue that the problem of illegitimate users is likely to be bigger with monetary than with non-monetary subsidies. This explains why a cost argument, both in terms of program costs and misallocation costs, might reverse our core finding that funding dominate founding policies.

\subsection{Implications for Further Research}

Our theory generates a host of new empirical predictions, and inspires interesting avenues for further empirical research. We group our discussion into three themes: $(i)$ the behavior of entrepreneurial angels, $(i i)$ the effect of entrepreneurship policies, and (iii) open ecosystem.

Our model highlights the importance of entrepreneurial experience for angel investing. This invites a more systematic empirical investigation of the behaviors of these key individuals. There is the question of who becomes an angel investor. Consider the set of founders, managers, and key employees of successful ventures that have experienced a successful exit, be it an acquisition or an IPO. The question is what do they do next? An empirical analysis might look at the incidence and determinants of these individuals becoming angel investors, as well as serial entrepreneurs (effectively investing in their own ventures). Also, our model looks at valuations and tax credits as determinants of the propensity to make angel investments. An empirical study could examine these and other important determinants of angel investing. The work of Cumming et al. (2016) is an interesting step in this direction. A complementary approach is to consider a representative sample of angel investors, and look at the behaviors of different types of angels. Our model is based on the premise that prior entrepreneurial experience imbues angel investors with useful tacit knowledge. This opens up new avenues for empirically investigating how entrepreneurial angels differ from their non-entrepreneurial peers: Do they select different types of companies, at different stages? Do they become more actively involved in these companies, provide different advice, or make different decisions? And do they achieve better investment outcomes?

Our analysis calls for further empirical studies of entrepreneurship policies. At the core of our theory is a relative evaluation of alternative entrepreneurship policies. Currently the most common type of empirical analyses of entrepreneurship policies concerns program evaluations, which look at a single program in isolation and ask whether it achieves its objectives (see, for example, Gans and Stern (2003), Hellmann and Schure (2010), Lerner (1999), or Zhao and Ziedonis (2012)). However, our theory suggests a more ambitious empirical agenda. Beyond individual program evaluations, policy makers need to think about policy design. This involves 
a relative comparison of the effects of alternative policies. Our analysis suggests that one of the challenges here is that different policies are applied to different populations of firms, at different stages of the entrepreneurial process. Another important challenge is that policies interact with each other, prompting questions to what extent different policies complement or substitute each other.

There is ample room for research on open ecosystems. A first set of questions relates to the role of foreign investors. Some prior literature explores when venture capitalists invest abroad and how (see Bottazzi et al. (2016), or Chemmanur et al. (2016)). The current model suggests going one step further and asking how these foreign investments affect the development of domestic ecosystems. A second set of empirical questions concerns brain drain. Surprisingly little is known about this: Which entrepreneurs leave? Under what circumstances, and at what stage? Where do they go? What effect does government policy have on their decisions?

Our model also opens up new avenues for further theoretical research. First, we believe that while our analysis identifies two important classes of entrepreneurship policies, future research could delve deeper into the details of these policies. Within each of our two policy categories there are interesting nuances between different policies; and beyond our two categories, there are many other entrepreneurship policies not considered here. Second, our analysis of intergenerational linkages focuses on one specific link, namely the transition of successful entrepreneurs to become angel investors. Future research might consider additional intergenerational linkages, such as the role of failed entrepreneurs. Third, for tractability reasons our model has obvious limitations, such as homogeneous venture opportunities of a fixed size, and a perfectly competitive investment market. Relaxing those assumptions might generate additional insights, including how different policies affect the level of competition in product and investment markets. Finally, a comprehensive formal analysis of open ecosystems remains beyond the scope of this paper. Of particular interest would be a more comprehensive analysis that includes both financial and human capital flows, thus also addressing the issue of entrepreneurial brain drain.

\section{Conclusion}

This paper builds a formal model of the market for financing entrepreneurial ventures, to examine the effects of two canonical entrepreneurship policies: founding policies that encourage entry by entrepreneurs, and funding policies that encourage financing by investors. The model recognizes the importance of tacit knowledge for investing in entrepreneurial ventures, and argues that this is mainly acquired through prior entrepreneurial experience. The supply of capital 
is therefore dependent on the wealth generated by prior generations of entrepreneurs. We show that this has a profound influence on the market equilibrium, and the impact of entrepreneurship policies. 


\section{References}

Admati, A. and P. Pfleiderer, 1994. Robust financial contracting and the role of venture capitalists. Journal of Finance 49, 371-402.

Agarwal, R., R. Echambadi, A. Franco, and M. B. Sarkar, 2004. Knowledge Transfer through Inheritance: Spin-out Generation, Growth, and Survival. Academy of Management Journal 47(4) 501-522.

Aghion, P., U. Akcigit, A. Bergeaud, R. Blundell, and D. Hémous, 2015. Innovation and Top Income Inequality. NBER Working Paper 21247.

Agrawal, A., C. Catalini, and A. Goldfarb, 2016. Are Syndicates the Killer App of Equity Crowdfunding?. California Management Review 58(2) 111-124.

Aizenman, J. and J. Kendall, 2012). The Internationalization of Venture Capital. Journal of Economic Studies 39(5), 488-511.

AngelList, 2016. Valuations are reported at https://angel.co/valuations.

Arora, A., A. Fosfuri, and T. Rønde, 2017. Waiting for the payday? The market for startups and the timing of entrepreneurial exit. Mimeo, Duke University.

Atomico, 2016. The State of European Tech, http://www.atomico.com/state-of-european-tech/2016.

Audretsch, D., I. Grilo, and R. Thurik (eds.), 2007. Handbook of Research on Entrepreneurship Policy, Edward Elgar, Cheltenham, UK.

Avnimelech, G., M. Kenney, and M. Teubal, 2005. A Life-Cycle Model for the Creation of National Venture Capital Industries. In E. Guilani, R. Rabellotti, and M. Dijk (Eds.). Clusters Facing Competition: The Importance of External Linkages (London: Ashgate): 195-214.

Axelson, U. and M. Martinovic, 2015. European Venture Capital: Myths and Facts. Mimeo, London School of Economics.

Bottazzi, L., M. Da Rin, and T. Hellmann, 2016. The Importance of Trust for Investment: Evidence from Venture Capital. Review of Financial Studies 29, 2283-2318.

Brander, J., Q. Du, and T. Hellmann, 2015. The Effects of Government-Sponsored Venture Capital: International Evidence. Review of Finance 19(2), 571-618.

Canidio, A. and P. Legros, 2015. The Value of Entrepreneurial Failures: Task Allocation and Career Concerns. Mimeo, University of Bruxelles.

Casamatta, C. and C. Haritchabalet, 2007. Experience, screening and syndication in venture capital investments. Journal of Financial Intermediation 16, 368-398.

Cassiman, B. and M. Ueda, 2006. Optimal Project Rejection and New Firm start-ups. Management Science 52, 262-75.

Chemmanur, T., T. Hull, and K. Krishnan, 2016. Do Local and International Venture Capitalists Play well Together? The Complementarity of Local and International Venture Capitalists. 
Journal of Business Venturing, forthcoming.

Cumming, D., U. Walz, and J. C. Werth, 2016. The Dynamics of Entrepreneurial Careers in High-tech Ventures: Experience, Education, and Exit. SAFE Working Paper Series, No. 122, Goethe University Frankfurt.

Da Rin, M., T. Hellmann, and M. Puri, 2013. A Survey of Venture Capital Research. In: Constantinides, G., M. Harris, and R. Stulz (eds.) Handbook of the Economics of Finance, Vol 2, Amsterdam, North Holland.

Decker, R., J. Haltiwanger, R. Jarmin, and J. Miranda, 2014. The Role of Entrepreneurship in US Job Creation and Economic Dynamism. Journal of Economic Perspectives 28(3), 3-24.

Delgado, M., M. Porter, and S. Stern, 2010. Clusters and Entrepreneurship. Journal of Economic Geography 10, 495-518.

Di Maio, M., G. Fabbri, and V. Lombardo, 2016. Heterogeneous Entrepreneurs, Government Quality and Optimal Industrial Policy. Mimeo, University of Naples.

Duruflé, G., T. Hellmann, and K. Wilson, 2018. From Start-up to Scale-up: Examining Public Policies for the Financing of High-Growth Ventures. In: Mayer, C., S. Micossi, M. Onado, M. Pagano, and A. Polo. (eds.) Finance and Investment: The European Case, forthcoming, Oxford: Oxford University Press.

Egger, P. and C. Keuschnigg, 2015. Innovation, Trade, and Finance. American Economic Journal: Microeconomics 7(2), 121-157.

Ellison, G., E. Glaeser, and W. Kerr, 2010. What Causes Industry Agglomeration? Evidence from Coagglomeration Patterns. American Economic Review 100(3), 1195-1213.

Färnstrand Damsgaard, E., P. Hjertstrand, P.-J. Norbäck, L. Persson, and H. Vasconcelos, 2016. Why Entrepreneurs Choose Risky R\&D Projects - but still not risky enough. CESifo Working Paper, No. 6138.

Forrest, C., 2014, How the 'PayPal Mafia' Redefined Success in Silicon Valley. Tech Republic http://www.techrepublic.com/

Gans, J. S., 2017. Negotiating for the Market. In: Furman, J., A. Gawer, B. S. Silverman, and S. Stern (eds.) Entrepreneurship, Innovation, and Platforms (Advances in Strategic Management), Vol. 37, Emerald Publishing Limited, pp. 3-35.

Gans, J. and S. Stern, 2003. When does Funding Research by Smaller Firms Bear Fruit? Evidence from the SBIR Program. Economics of Innovation and New Technology 16, 361-384.

Glaeser, E. L., W. R. Kerr, and G. A. M. Ponzetto, 2010. Clusters of Entrepreneurship. Journal of Urban Economics, 67(1), 150-168.

Gompers, P., A. Kovner, J. Lerner, and D. Scharfstein, 2010. Performance Persistence in Entrepreneurship. Journal of Financial Economics 96(1), 18-32. 
Gompers, P. and J. Lerner, 2000. Money Chasing Deals? The Impact of Fund Inflows on Private Equity Valuation. Journal of Financial Economics 55, 281-325.

Gompers, P., J. Lerner, and D. Scharfstein, 2005. Entrepreneurial Spawning: Public Corporations and the Genesis of New Ventures, 1986 to 1999. Journal of Finance 60, 577-614.

Green J. R. and S. Scotchmer, 1995. On the Division of Profit in Sequential Innovation. RAND Journal of Economics 26(1), 20-33.

Guiso, L., L. Pistaferri, and F. Schivardi, 2015. Learning Entrepreneurship from Other Entrepreneurs. NBER Working Paper 21775.

Hellmann, T. and E. Perotti, 2011. The Circulation of Ideas in Firms and Markets. Management Science 57(10), 1813-1826.

Hellmann, T. and P. Schure, 2010. An Evaluation of the Venture Capital Program in British Columbia. Report prepared for the BC Ministry of Small Business, Technology and Economic Development.

Hellmann T. and V. Thiele, 2014. Friends or Foes? The Interrelationship between Angel and Venture Capital Markets. Journal of Financial Economics, 115(3), 639-653.

Hsu, D., 2007. Experienced Entrepreneurial Founders, Organizational Capital, and Venture Capital Funding. Research Policy 36, 722-741.

Inderst, R. and H. Müller, 2004. The Effect of Capital Market Characteristics on the Value of Start-up Firms. Journal of Financial Economics 72, 319-356.

Jovanovic, B., 1982. Selection and the Evolution of Industry. Econometrica 50(3), 649-670.

Kenney, M., 2000. Understanding Silicon Valley: Anatomy of an Entrepreneurial Region. Stanford University Press, Stanford, CA, US.

Kerr, W. R., J. Lerner, and A. Schoar, 2014. The Consequences of Entrepreneurial Finance: Evidence from Angel Financings. Review of Financial Studies 27(1), 20-55.

Keuschnigg, C. and S. B. Nielsen, 2003. Tax Policy, Venture Capital, and Entrepreneurship. Journal of Public Economics 87, 175-203.

Keuschnigg, C. and S. B. Nielsen, 2004. Start-ups, Venture Capitalists, and the Capital Gains Tax. Journal of Public Economics 88, 1011-1042.

Klepper, S. and S. Sleeper, 2005. Entry by Spinoffs. Management Science 51, 1291-1306.

Kremer, M., 1998. Patent buyouts: A mechanism for encouraging innovation. Quarterly Journal of Economics 113(4), 1137-1167.

Lafontaine, F. and K. Shaw, 2016. Serial Entrepreneurship: Learning by Doing? Journal of Labor Economics 34(2), 217-254.

Landier, A., 2006. Entrepreneurship and the Stigma of Failure. Unpublished working paper, University of Toulouse. 
Leleux, B. and B. Surlemont, 2003. Public versus Private Venture Capital: Seeding or Crowding Out? A Pan-European Analysis. Journal of Business Venturing 18, 81-104.

Lerner, J., 1999. The Government as Venture Capitalist: the Long-run Impact of the SBIR Program. Journal of Business 72, 285-318.

Lerner, J., 2008. Boulevard Of Broken Dreams: Why Public Efforts To Boost Entrepreneurship And Venture Capital Have Failed. Princeton University Press, Princeton.

Lerner, J. and A. Schoar, (Eds.), 2010. International Differences in Entrepreneurship, National Bureau of Economic Research, Cambridge, MA, US.

Lerner, J., A. Schoar, S. Sokolinski, and K. Wilson, 2018. The Globalization of Angel Investments: Evidence across Countries. Journal of Financial Economics 127(1), 1-20.

McKenzie D. and C. Woodruff, 2014. What Are We Learning from Business Training and Entrepreneurship Evaluations Around the Developing World? World Bank Research Observer 29(1), 48-82.

Michelacci, C. and J. Suarez, 2004. Business Creation and the Stock Market. Review of Economic Studies 71, 459-481.

Lee, C.-M., W. Miller, M. Gong Hancock, and H. Rowen, 2000. The Silicon Valley Edge: A Habitat for Innovation and Entrepreneurship. Stanford University Press, Stanford, California.

Piketty, T., 2014. Capital in the Twenty-First Century. Harvard University Press, Boston, MA, USA.

Poterba, J., 1989a. Venture Capital and Capital Gains Taxation. Tax Policy and the Economy Vol. 3, edited by L. H. Summers. Cambridge, MA: MIT Press. 47-673.

Poterba, J., 1989b. Capital Gains Tax Policy Toward Entrepreneurship. National Tax Journal 42(3), 375-390.

Rauch, J., 2015. Dynastic Entrepreneurship, Entry, and Non-compete Enforcement. NBER Working Paper 21067.

Saxenian, A., 1994. Regional Advantage: Culture and Competition in Silicon Valley and Route 128. Harvard University Press, Cambridge, MA.

Segal, I. and M. Whinston, 2007. Antitrust in Innovative Industries. American Economic Review 97(5), 1703-1730.

Senor D. and S. Singer, 2009. Start-up Nation: The Story of Israel's Economic Miracle. Grand Central Publishing, NY, US.

Startup Genome, 2017. Global Startup Ecosystem Report, www.startupgenome.com.

Van Osnabrugge, M. and R. J. Robinson, 2000. Angel Investing: Matching Start-up Funds with Start-up Companies. San Francisco, CA: Jossey-Bass. 
Wilson, K., 2011. Financing High-Growth Firms: The Role of Angel Investors. OECD Publishing.

Wilson, K., 2015, Policy Lessons from Financing Young Innovative Firms. OECD Science, Technology and Industry Policy Papers No. 9. OECD Publishing. doi: 10.1787/5js03z8zrh9pen.

Wilson, K. and F. Silva, 2013. Policies for Seed and Early Stage Finance. OECD Science, Technology and Industry Policy Papers, No. 9. OECD Publishing. doi: 10.1787/5k3xqsf00j33-en.

Zhao, B. and R. Ziedonis, 2012. Bridging the Funding Gap for Technology Startups? Evidence from Michigan’s R\&D Loan Program. Mimeo, Boston University. 